Article

\title{
A Comparative Study of the Configuration and Functions of Outdoor and Semi-Outdoor Space in Schools from the Traditional to the Contemporary Period Based on Evaluating the Role of the Governing Educational System
}

\author{
Fatemeh Fallah Tafti *(D) and Hamid Mirjany Arjanan
}

Citation: Fallah Tafti, F.; Mirjany Arjanan, H. A Comparative Study of the Configuration and Functions of Outdoor and Semi-Outdoor Space in Schools from the Traditional to the Contemporary Period Based on Evaluating the Role of the Governing Educational System. Sustainability 2021, 13, 12782. https://doi.org/ $10.3390 /$ su132212782

Academic Editor: Gerardo Maria Mauro

Received: 30 August 2021

Accepted: 27 October 2021

Published: 19 November 2021

Publisher's Note: MDPI stays neutral with regard to jurisdictional claims in published maps and institutional affiliations.

Copyright: (c) 2021 by the authors. Licensee MDPI, Basel, Switzerland. This article is an open access article distributed under the terms and conditions of the Creative Commons Attribution (CC BY) license (https:/ / creativecommons.org/licenses/by/ $4.0 /)$.
Department of Architecture, Faculty of Art and Architecture, Yazd University, Yazd P.O. Box 89195-741, Iran; h.mirjany@yazd.ac.ir

* Correspondence: fatemehfallah73@gmail.com

\begin{abstract}
The present study, based on a case study, aims at addressing the functional and morphological evolutions in outdoor and semi-outdoor spaces in Yazd schools over time, through educational developments. The approach followed in this study is to connect the changes in the spatial structure of outdoor space in schools to the evolutions in the educational system. To this end, this paper develops five hypotheses and employs qualitative and computational research methods to evaluate the functions and spatial configuration of the outdoor spaces of six schools, constructed between the 18th and 20th CE centuries, in Yazd. A mathematical method drawn by "space syntax" is adopted to measure the spatial features of the outdoor spaces of schools, and a field study is used to identify the relationship between the functional process of these configurations and their governing educational principle. The results show that the configuration of the traditional schools, built between the late 18th and 19th centuries, in Yazd was formed based on the active educational role of outdoor and semi-outdoor spaces, followed by the governing educational policies. Moreover, the outdoor and semi-outdoor spaces are not only the main spaces where social activities are held in schools, but also are complementary elements to the indoor educational spaces. Meanwhile, in modern schools, constructed in the early 20th century, and contemporary schools, constructed in the late 20th century, the spatial configuration of schools has changed and the importance of outdoor and semi-outdoor spaces in these schools has significantly devaluated due partially to the evolution of the modern educational system compared to traditional schools. By identifying the features of three different school building typologies, as well as their outdoor space functions, this paper provides useful knowledge for future school designing and planning in Yazd.
\end{abstract}

Keywords: outdoor space; semi-outdoor space; educational function; education system; spatial configuration; space syntax; Yazd city

\section{Introduction}

According to studies by environmental psychologists and Gifford's theories [1], humans constantly interact with their environment. As a result, social behavior cannot develop individually, but requires interaction with the environment. Psychologists generally believe that psychological phenomena and their variations are the result of interactions between humans and the environment. In this respect, schools are of significant importance, because students spend most of their time there during a momentous period of personality formation. Given that educational spaces affect the quality of learning and the other achievements of students, many studies have been conducted in the fields of environmental psychology and education. According to these investigations [1,2], a teacher is involved in the education and performance of students, alongside several other factors, including the physical space of education. The quality of school space has strong and 
long-term effects on the academic performance of students [3]. Therefore, studying their performance and learning without considering the educational space leads to defective results [4]. Accordingly, the outdoor space or yard is one of the key elements in schools that have always been a sign of school architecture, as seen in the primary buildings of all schools. In modern-day schools, the role of outdoor spaces in schools and their qualities has received special attention within educational policies. From these policies, it has become apparent that the schoolyard can exert positive influences on students' formal and informal learning [5-7].

As a matter of fact, on the one hand, some works have shown the great impact of school outdoor space, as places where students spend their informal learning and break times, on improving social skills [8-10], physical and mental health [11], and disposition towards education [11].

On the other hand, outdoor spaces are proper resources for formal learning $[8,12,13]$. The research shows a direct relationship between outdoor educational space and student learning [8,13-17]. These spaces can perform as outdoor classrooms explored by students that provide opportunities to experience and interact with real-world cases $[7,8,14,18]$. School outdoor space provides advantages in the teaching and learning process. For instance, it can improve perceptibility through creating different learning opportunities from the potentials of the site $[7,9,15,19]$, increase the interest and motivation of students because of the outdoor attractions [7,12], allow using different learning methods, and encourage cooperation between students and teachers [7-9]. Therefore, outdoor education allows a wide range of direct experiences through interaction with the living environment, as well as improving the quality of learning and preparing the students to participate in social interactions [20]. Furthermore, the outdoor learning process allows students to practice their team-working ability $[4,6,21]$. In this respect, since collaborative learning is much more attractive for students and is more effective on the activity of the mind [2,22,23], it motivates students for the process of mental action and reaction and thus promotes learning at a sustainable level [24-26].

In spite of the importance of the physical space of schools, the demand of contemporary Iranian civil society for the expansion of the education sector, especially mass education, has led to the construction of numerous schools but without any attention paid to the significance of the spatial configuration of a school in students' development. Despite many changes and improvements in the content of education, the spatial pattern of schools has had no positive evolution during the last century. The predominant pattern in the design of recently constructed schools ignores the functional capabilities of outdoor spaces in education, and schoolyards are just planned as places for breaks between lessons, resulting in relatively small and asphalt-covered spaces [27] with limited elements and equipment for games and physical activities, as well as a small amount of vegetation $[27,28]$. This issue is prominent in the historical city of Yazd, an Iranian city known by its courtyard buildings and recognized as a World Heritage Site by UNESCO, which has witnessed significant structural changes in educational spaces during the traditional period, between the 18th and 19th centuries, to the modern period, early 20th century, and the contemporary period, the late 20th and early 21st centuries after the Islamic Revolution in Iran.

In addition to morphological changes, the structure of the educational system has also considerably changed during these periods. In the traditional view, the school can be defined as an institution for education in which traditional Islamic sciences are taught such as hadith, commentary, and jurisprudence. The educational system of the traditional period significantly relied on discussion between participants sat in a loop formation [29]. In this method, the teaching process includes a lecture by the instructor and a discussion about the presented issues by the loop members, especially those who sit close to the instructor. Thereafter, the discussion is continued by all members of the loop more actively even after the end of class [30]. Additionally, in this educational system, courses can be useful for advanced and elementary students, as well as the public, because of the religious 
content of the courses. Therefore, in this educational system, the last chain of the loop model is formed by the public, given that the public can be educated [31] (Figure 1a).

Since the late 19th century, Iran has undergone extensive socio-political changes following a series of domestic and international developments. The result was straying from traditional customs to follow the Western culture, including the modern education system. In other words, in this period, from the first Pahlavi onward, the role of mullahs for teaching was eliminated and Western graduates became the leaders of the educational system [32]. In the modern educational system, a new definition of "teaching" and "learning" was formed, and the general method of teaching was changed. The main purpose of this type of teaching method, which is still common in contemporary Iranian schools, is to transfer information from a knowledgeable person (teacher) to an ignorant person (student) [31]. This program introduces a new concept of education, that is, the direct transfer of information from teacher to student. In this teacher-centered method, students sit in front of the teacher while active communication, participation, and discussion rarely happen between students and teachers [30] (Figure 1b).

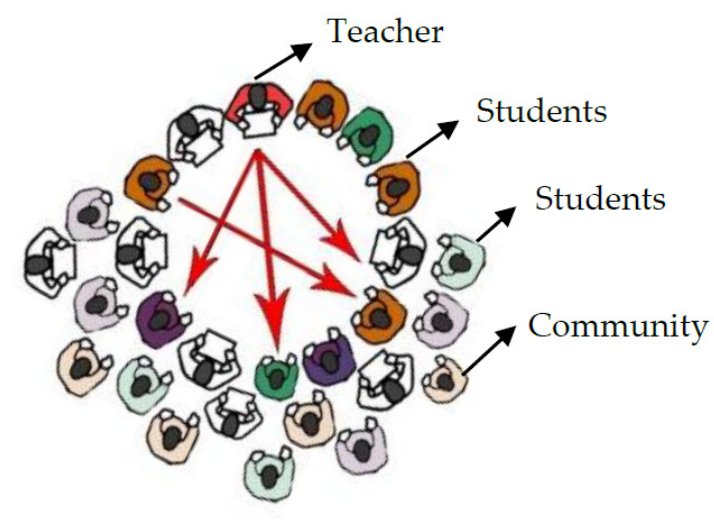

a

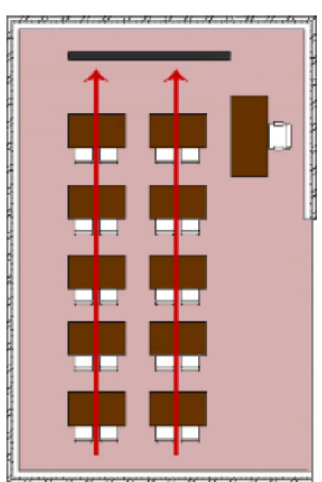

b

Figure 1. Comparison of teaching methods in traditional and modern education systems: (a) teaching methods in the traditional education system and (b) teaching methods in the modern educational system Adapted with permission from ref. [31]. 2010 Irvani.

Given the significant transitions in the spatial and educational structure of Yazd schools and the importance of outdoor spaces in schools and Yazd's domestic architecture, this study considers the evaluation of the outdoor and semi-outdoor space of six schools in different periods of Yazd, examined in terms of configuration and educational function from the view of historical-educational developments. In fact, it aims at theoretically and methodologically contributing to the argument on how the functions and typology of school outdoor spaces in Yazd have changed and whether these transitions can be attributed to changes in educational system. In this respect, six schools in use belonging to the mentioned periods were evaluated. Khan and Imam Khomeini schools were selected as the traditional schools, constructed between the late 18th and 19th centuries; Iranshahr and Markar schools as the only samples dating back to the educational system revolution of Yazd, early 20th century; and Olia and Javad-al-Aemeh schools as the contemporary schools, constructed after the Islamic Iranian Revolution, late 20th century. To address these questions, the space syntax method was used to analyze the spatial features of outdoor space in schools. In addition, the field study method was adopted to identify the functions of outdoor space, as well as the principal features of the educational system, in schools. This duplication in the use of evaluation methods provides a better understanding of the morphology and role of school outdoor spaces in each period in order to diagnose any typologies more suitable for school design in Yazd. 


\section{Research Literature}

Of all studies conducted in the field of the architectural development of schools, some are briefly discussed in the following:

Several studies addressed the history of developments in Iranian schools. For example, Samiazar [33] studied the history of physical developments in Iranian schools in four different periods of Sassanid, 266-637 AD, Seljuk, 1030-1181 AD, Safavid, 1501-1722 AD, and the contemporary period, from the late 19th to the 20th century, using a documentary research method. He concluded that subsequent to the changes in the educational system in Iran, the schools' architectural plans had to evolve to meet the requirements of the new educational policies. This scholar believes that following the cultural and educational changes that occurred in Iran during the 19th century leading to architectural changes in schools, there were no conscious thoughts and careful considerations on the essential prerequisites for making these major changes. Irvani [31] also explained the architectural and educational developments of Iranian schools in five different periods: before Islam, $330 \mathrm{BC}$ to 641 AD, after the arrival of Islam, 700 AD, Safavid, 1514 AD, the contemporary, 1871-1981 AD, and the present, 1971 AD till now, employing documentary and comparative research methods. According to the results of this study, the architecture of schools in Iran has roots in the evolution of educational policies, and the evolution of the schools in the contemporary period has been a poor imitation of Western schools rather than an innovative trend. The author believes that despite the significant advancement in educational content, programs, and methods, the role of the educational environment has been neglected in the contemporary era. Khodabakhshi et al. [34] investigated the architectural developments of three Iranian schools during the three periods of tradition, mid 19th century, revolutionary, late 19th century, and modernity, early 20th century, based on the governing educational system, adopting a historical research method. The results indicate that the school educational system has a direct impact on school educational spaces during these periods. Alaghmand et al. [35] conducted a comparative-analytical study on the architecture and content of Iranian schools in three periods of tradition, from the 15th to mid 19th centuries, revolutionary, late 19th century, and modernity, early 20th century. The results show that the architectural developments in Iranian schools during the revolution and modern periods have been due to the imitation of Western architecture.

Another group of studies examined the developments in the outdoor space of schools in Iran. For instance, Samiazar [36] compared the nature and function of the outdoor space of traditional Iranian schools, dating back to before the 20th century, and contemporary Iranian schools, constructed in the mid 20th century, with modern-day European schools. Finally, by comparing these three types of yards, he concluded that the different architectural designs of schoolyards have followed the three perspectives of education, including the traditional view related to the traditional schools of Iran, the classical view, and the modern view. According to the results of this study, the outdoor spaces of traditional Iranian and modern central European schools has had an active and dynamic role within the education process of students, while in contemporary Iranian schools, outdoor space does not have any educational role. Moreover, it is not considered in the formal education process. In addition, the outdoor spaces of the schools in the traditional period are allowed to be used by neighborhood residents and are the center of social activities. However, in the modern period, the outdoor space of the schools does not welcome residents. In another study, Tahersima et al. [27], through a field study, examined the role of open space in Iranian schools in three periods: traditional, early 18th century, transitional, mid 19th century, and modern, early 20th century. The results show that open space in traditional Iranian schools has played an active educational role. In fact, in the traditional schools, not only are the courtyards used for holding discussion loops, but residents also are allowed to participate in the discussion circles or ceremonies held in the schools. Meanwhile, open space in transitional and modern schools is free from any educational role and is used only during recreation. The authors believe that the changes in the function of outdoor spaces in Iranian schools stems from the evolution of the educational system. 
On the other hand, some scholars have tried to explore the principles related to different setting patterns in various spaces, based on a concept called space syntax. This method identifies the correlation of the spatial configuration with users' activities and socio-cultural activities [37]. Hillier and Hanson [38] introduced a method for modeling and analyzing spatial configuration, and presented an analysis of traditional settlement layouts, modern housing estates, and traditional and modern houses. Their analysis demonstrated the relationship among spatial configuration, social logic, and human activities. Space syntax has been used for analyzing different building groups in many studies. For example, Rashid et al. [39] carried out an axial analysis of space syntax in four distinct workplaces and discovered the relationship between the rate of interaction and office layouts. Kweon [40] evaluated two museums in the UK and discovered a correlation between the integration value and human flow. Haq [41] carried out an axial analysis of three hospitals and three types of survey: free wayfinding, cognitive map, and route choice, and found their relationships. Some studies also applied the space syntax method to analyze the spatial configuration of school buildings. For instance, De Jong [42] conducted a study on the spatial layout of school buildings and revealed that the spatial configuration of school places, including classes and other facilities, affects the movement patterns inside the schools. Nayeem [43] analyzed the accessibility and configuration of schools by employing different strategies to increase the integration of the specific area and found that if educational institutes are located in a highly integrated area, these will be within the network citizens' daily movement. Taguchi and Kishimoto [44] studied children's activities in the entire school's buildings to identify the impacts of spatial layout on children's activities by employing the space syntax method. The results show that there is an indirect relationship between the step depth of the spaces of the classrooms and the tendency of students (especially of lower grades) to spend their break times in those spaces. In another study, Kishimoto and Taguchi [45] studied 76 primary schools in Japan and found that spatial layouts with a higher rate of intelligibility generate more contact and interaction between students of different grades. Pasalar $[46,47]$ found that the spatial configuration of school buildings affects patterns of interaction and movement. School building layouts with a higher rate of accessibility, shorter walking distances, and highly visible public areas facilitate higher rates of incidental communications among pupils. According to these studies, productive spaces, such as atriums and corridors, connecting the main educational spaces, circulate and facilitate spatial relations, act as the driving force for movement patterns, and stimulate social activities among students. Mustafa and Rafeeq [48] analyzed three different floor plan typologies of elementary schools in Erbil through space syntax, as well as feedback assessments of the school staff, and evaluated the merits and demerits of each typology. With regard to research conducted on school buildings and mentioned in the literature, some gaps were detected that the current study aims to address.

i. While the first group of mentioned research has proposed multiple interpretations of the transformations of school building typologies in Iranian architecture over time, they have repeatedly used qualitative research methods to understand the spatial properties of school architectural plans and have less often adopted mathematical and computational methods to evaluate the spatial layouts of school buildings and their outdoor space based on educational system changes. In fact, this is not a straightforward proposition to assess. The properties of buildings are complex, and without measuring the networks of social and functional relations they create, the spatial changes cannot be validated.

ii. The spatial structure of Yazd's schools' outdoor space has been less studied in these works, whereas the central courtyard buildings are known to be one of the elements responsible for Yazd's UNESCO World Heritage status. 
iii. Although the research of the second part of the literature, using space syntax measurements, has analyzed the spatial configuration of school buildings in different aspects, they have mainly focused on the spaces around the classrooms, as well as spaces where circulations happen. There are limited studies considering the outdoor spaces of schools or even both exterior and interior spaces of schools.

iv. There has been limited research employing the field study research method to study and observe the differences in the functions of schools' outdoor spaces in different layouts, and the relationship between these functions and the governing educational system in the schools.

These gaps in our understanding of the spatial configuration and functions of schools' outdoor spaces in Yazd are the focus of this paper. To address these knowledge gaps, the current paper applies an architectural analytical method to measure the morphological features of Yazd's school buildings' outdoor and semi-outdoor spaces, spanning from the 18 th to 20th century. Moreover, the functions of outdoor and semi-outdoor spaces, as well as the governing educational system in the schools are identified through an observation and field study.

\section{Research Hypotheses}

Based on the identified knowledge gaps in the literature review, this paper attempts to examine five hypotheses, as follows:

i. There is a direct relationship between the educational policies governing in the schools and the functions served by the outdoor space of the schools to neighborhood residents.

ii. The degree of the relationship between the outdoor space of schools and other spaces, semi-outdoor spaces and classrooms in particular, has diminished in Yazd schools over time.

iii. The possibility of being a site of encounter has decreased in the outdoor spaces of Yazd schools over time.

iv. There is a direct relationship between the governing educational policies in the schools, i.e., teaching methods and course contents, and the functions of the outdoor spaces of the schools.

v. There is a direct relationship between the evolution of schools' outdoor space layouts and changes in educational policies in Yazd schools over time.

Despite some original dimensions of this study and its attempts to address some gaps in our understanding of schools' evolution in Yazd, it has several methodological limitations. As the focus is on typology and the functions of schools' outdoor spaces based on the evolution of the educational system, it does not consider some other cross-sectional variations, contextual issues, and environmental factors that might have been involved in transformations. As a matter of fact, this paper cannot offer any direct evidence about environmental and socio-cultural conditions, rather than governing educational policies in the schools. Instead, it only focuses on the mathematical and functional features of schools' outdoor spaces based on evaluating the changes in educational policies in the schools, which are central to many theories and interpretations of the significance of schools' outdoor spaces, as well as schools' morphological changes, in the historic city of Yazd.

\section{Methodology}

The present study, based on a case study, aims to conduct a comparative study on the development of the outdoor spaces of Yazd schools during three periods: traditional (from late Zand dynasty to Qajar period), late 18th and 19th centuries, modern (from late Qajar to Pahlavi period), early 20th century, and contemporary (after the Islamic Revolution until now), late 20th century until now. For this purpose, a qualitative method is employed to highlight their role and function in terms of the educational developments of each period, and a qualitative method is used to analyze the spatial properties of school buildings. The general approach of this study is to find out whether the transition basis of the spatial 
configuration and function of the outdoor spaces of schools could be attributed to the evolution of the educational system. In fact, not only does the current paper study the development of schools' outdoor spaces as a concept of space, but it also aims to analyze how the educational needs of each period might have affected the structural and functional features of schools' outdoor spaces.

In this paper, the role and spatial settings of outdoor space in Yazd schools are discussed in three scales: macro, median, and micro (Figure 2). The data on the macro and micro scale were collected by field study and the data on the median scale were collected via simulation and using space syntax theory. It is of note that applying both qualitative data and the space syntax technique was very effective for a more accurate understanding of relationships and concepts. In other words, these two datasets are complementary, such that spatial analysis addresses the function of the spatial configuration of structures, while qualitative data provide significant experiences that explain the functional process of these configurations [2].
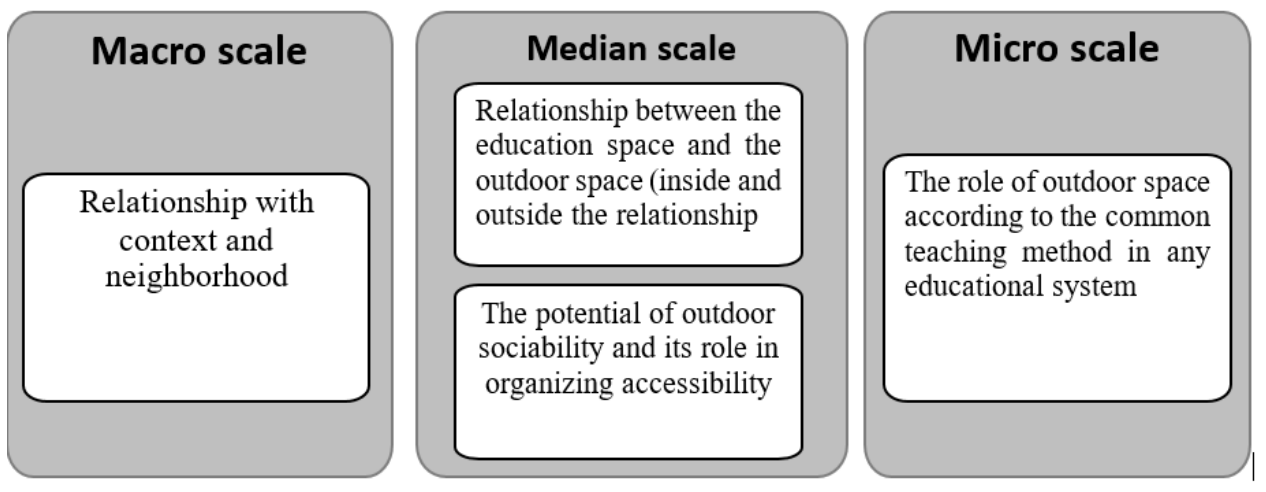

Figure 2. Framework of research.

\subsection{Case Selection}

To choose the samples, in the first place, there were four main criteria:

i. The cases are largely in their original condition, not having been significantly adjusted or reformed over time.

ii. Their urban and neighborhood context are not considerably degraded by new development, as well as other factors such as natural disasters.

iii. They are examples of the period in which they were constructed.

iv. They are still in use as educational buildings and follow their original educational system.

\subsubsection{Selection of the Traditional and Modern Case Studies}

To select the samples related to the traditional and modern periods, the list of school names was retrieved from documents of the Cultural Heritage Organization of Yazd. According to the data, there were limited cases meeting all the mentioned criteria. In fact, Khan and Imam Khomeini schools were the only schools built in Yazd from the late Zand dynasty to the middle of the Qajar period fulfilling the criteria. This was also the case with the samples for the modern period. Iranshahr and Markar schools, constructed in the modern period in Yazd and coinciding with the educational revolution in this city, were the only schools meeting the criteria. Therefore, due to the limited number of schools of these two periods, all these schools were selected for investigation.

\subsubsection{Selection of the Contemporary Case Studies}

By referring to the sites of the Yazd Ministry of Education districts 1 and 2, the list of secondary schools in Yazd established after the Islamic Revolution was obtained to select samples of the contemporary period. In the next phase, both open and closed situations of these schools were monitored through Google Maps. Afterward, 20 samples, having the most frequent and repeated general and basic layouts, were selected for the 
primary analysis. Since there were four main criteria in case selection, by referring to the Yazd School Renovation Organization and consulting with the experts, the schools whose original function had been changed, as well as the ones not meeting the three other criteria, were eliminated from the list. Since the majority of these 20 cases had been adapted or modified in recent years, just eight schools, complying with the four requirements, were selected and generally studied through a two-week field study, which was the first phase of field study (see Section 4.2.1), clarifying that the basic layout of schools, how the open and closed spaces are arranged and organized and how these spaces are interconnected, as well as the functions held in the outdoor spaces of schools, were strikingly similar. Moreover, the spatial configuration of the outdoor spaces of the eight samples was analyzed through a convex map analysis of space syntax, revealing roughly similar average ratios of connectivity, integration, and mean depth. Eventually, due to the significant similarities among the eight samples, as well as the limitation on the number of schools that the field study could be performed on, two of them, Olia and Javad-al-Aemeh schools, were randomly selected as the case studies built in the contemporary period.

\subsection{Field Study}

The fieldwork was divided into two phases. The first was a 16-day observation in October, 2018. The second phase was in November and December 2018, January and February 2019, and April and May 2019. The two phases are discussed below.

\subsubsection{Phase 1}

- $\quad$ Time period: October 1-October 16 (Schools are off on Thursdays and Fridays in Iran).

- Objectives: In phase 1, the eight primary samples built in the contemporary period were visited for four main reasons:

i. To understand the logistics for the main field study in November and December.

ii. To observe the basic layout of the schools and understand how the different spaces are interconnected.

iii. To observe what activities are held in the outdoor space of the schools.

iv. To select the final contemporary case studies for the main research.

- Process: To achieve the objectives, each school was visited for two days, once each week, during the mentioned time period from 8 A.M. to 2 P.M. (the whole school time) in order to observe and obtain a general understanding of the activities taking place in the outdoor space of the schools.

- Results: Primary observations suggested that the outdoor spaces of schools mainly served similar functions, such as providing students with a space for spending break times and taking fitness courses. Moreover, it was revealed that the floor plans of the eight schools followed the same basic layout, which was simultaneously confirmed by analytical analyses through the space syntax technique as well.

\subsubsection{Phase 2}

- Time period: There were two main criteria for observation dates in the schools:

i. The main priority in this phase was to visit the sites on all days of the week to be sure that the observations included all the activities taking place during a typical week in the schools.

ii. The schools needed to be visited in the three seasons of a whole school year to diminish the possibility of overlooking some seasonal activities taking place in the outdoor space of the schools.

The details of visits and observations are listed in the table below (Table 1). 
Table 1. Dates of fieldworks and observations.

\begin{tabular}{|c|c|c|c|c|c|c|}
\hline & Khan & $\begin{array}{l}\text { Imam } \\
\text { Khomeini }\end{array}$ & Markar & Iranshahr & Javad-al-Aemeh & Olia \\
\hline Nov to Dec 2018 & $\begin{array}{c}\text { Nov } 3 \text { to Nov } 6 \text { (Nov } 7 \\
\text { was a legal holiday) }\end{array}$ & Nov 10 to Nov 14 & Nov 17 to Nov 21 & $\begin{array}{l}\text { Nov } 24 \text { to Nov } 28 \\
\text { (except Nov 25, which } \\
\text { was a legal holiday) }\end{array}$ & Dec 1 to Dec 5 & Dec 8 to Dec 12 \\
\hline Jan to Feb 2019 & Jan 26 to Jan 30 & Feb 2 to Feb 6 & $\begin{array}{c}\text { Feb } 10,12 \text {, and } 13 \\
\text { (Feb } 9 \text { and } 11 \text { were } \\
\text { legal holidays) }\end{array}$ & Feb 16 to Feb 20 & Feb 23 to Feb 27 & Mar 2 to March 6 \\
\hline Apr to May 2019 & Apr 6 to Apr 10 & Apr 13 to Apr 17 & $\begin{array}{c}\text { Apr } 20 \text { to Apr } 24 \\
\text { (except Apr 21, } \\
\text { which was a } \\
\text { legal holiday) }\end{array}$ & Apr 27 to May 1 & May 4 to May 8 & May 11 to May 15 \\
\hline $\begin{array}{c}\text { Complementary } \\
\text { Observations }\end{array}$ & 18 May 2019 & 19 May 2019 & 20 May 2019 & 21 May 2019 & 22 May 2019 & 25 May 2019 \\
\hline
\end{tabular}

- Objectives: In this phase, the main tasks were to map the six selected case studies for four main reasons:

i. To observe whether the outdoor space of the schools was interconnected with their neighborhood areas.

ii. To observe whether there were any activities being taken part in by residents in the outdoor space of the schools.

iii. To observe the educational functions served by the outdoor spaces of the schools (whether the outdoor spaces of the schools were used for holding classes).

iv. To observe whether there was a relationship between the educational policies implemented in the schools and the functions served by the outdoor space of the schools.

- Process: To fulfill the objectives, the case studies were visited on the mentioned dates from 8 A.M. to 2 P.M. to capture the functions of the outdoor space of the schools and record the observations by note taking and photography. At first, schools were visited on the mentioned dates and the outdoor space of the schools was thoroughly mapped. Every activity carried out by students, staff, and the community in the outdoor space of the schools was recorded. Moreover, the observations were outlined at the end of each day. In the next stage, when all six schools had been visited for an entire week in every season, fall, winter, and spring, each school was again visited for just one day. The main purpose of this stage was to complement the data collection if something had been missed, as well as to ask the schools' principal to confirm or complement the collected data. The principals were given an outline of the data captured during the observations and asked to comment if there were any inconsistencies in the information, and add any other activities held in the schools outdoor space or functions served by the outdoor spaces. When the accuracy of the obtained data was confirmed by the schools' principal, the data gathered from both the qualitative and quantitative methods, along with the educational policies adopted in the schools, were indicated.

\subsection{Space Syntax: Indexes and Methods of Spatial Analysis}

Space syntax is an analysis tool for architecture and urban planning [38]. This theory was first introduced in the late 1970s and early 1980s in London [38,49-51]. According to this approach, the architectural space is influenced by the social framework [49-51]. Accordingly, space syntax explains how the concept of spatial configuration expresses a social or cultural meaning $[37,51]$. Solely focusing on spatial features, space syntax was the stimulus for a paradigm shift in architectural analysis, eliminating the standard conventions seeking to comprehend architecture in terms of shape, style, and geography. Instead, space syntax presents a comprehension of architecture that is inherently topological and relational [52]. 


\subsubsection{Data Analysis Method}

There are three types of analysis methods in the space syntax technique. In this research, the convex map method was used, as this method is common in studying the arrangement of programmatic spaces and architectural plans and spaces [37]. This method, first, simplifies the plan by creating connected two-dimensional convex spaces, called a convex map. A convex map is a map in which each point of space can be seen from any other site. Moreover, any space that is not convex is divided to obtain the lowest number with the largest volume of convex space covering the entire plan. When the map is completed, each convex space is converted to a node in the graph, and if there is direct access between these convex spaces, the nodes are connected by edges. Thus, the plan is converted into a graph that allows mathematical analysis using graph theory techniques [37,48,53] (see Figure 3).

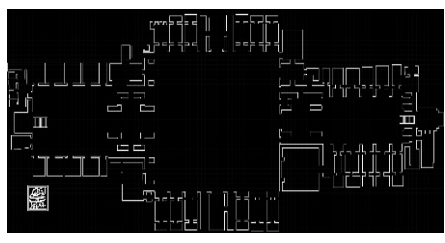

(a)

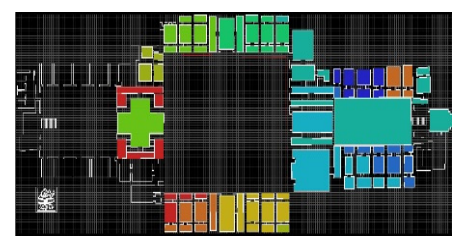

(b)

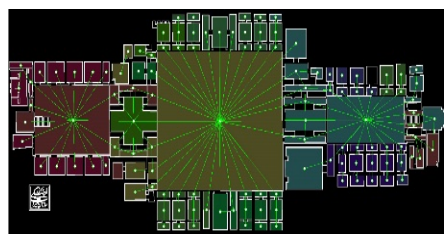

(c)

Figure 3. A convex map: (a) building plan, (b) drawing convex spaces, (c) linking interconnected convex spaces.

Depthmap software developed by Turner at the University College London (UCL) is among the various tools in space syntax for analyzing the structure of spatial configuration [54]. In this study, Depthmap X-version was used to draw convex maps of schools, including outdoor and indoor spaces for analysis of the structure of the spatial configuration of selected samples, to find the relationship between school spatial settings and education system as one of the cultural components.

\subsubsection{Measurement Indicators}

There are various indexes in the space syntax technique to evaluate the spatial configuration of the building. In the present study, two indexes of step depth and integration were used to study the evolution of the role of outdoor spaces and the type of spatial settings of selected schools. Both indexes are briefly described as follows:

i. Step depth: The depth between two spaces is defined as "the least number of syntactic steps in a graph that are needed to connect one from to the other" [38,55]. In other words, the step depth itself may be viewed as the number of turns (plus one) or spaces that it takes to travel from the current location to any other location within the plan [54]. A measure of syntactical step depth represented in convex space maps reveals the level of complexity of spatial configuration. According to this measure, the more steps one must take to move from point $A$ to point $B$, the more complex the configuration becomes. As a result, higher degrees of segregation between spaces will be established [2].

ii. Integration: Integration describes the average depth of space to all other spaces in the system. The spaces of a system can be ranked from the most integrated to the most segregated [55]. Integration is a normalized measure of distance from any space of origin to all others in a system. In general, this method is used to calculate how close the origin space is to all other spaces [38]. Hence, it sometimes is regarded as the index of spatial accessibility $[56,57]$ or availability, since it refers to how space is connected with other spaces in its surroundings [49]. In the space syntax technique, integration is the most important index for predicting the movement of individuals [50,58,59]. Integration is a parameter to find the relationship between spaces and users. This parameter can be used to predict the co-presence potential of space, because the value of integration is directly related to the volume of movement and the presence of 
people in a given space. Moreover, users generally are directed to more integrated spaces [49]. Simply put, people are more likely to meet each other in the more integrated spaces, and less integrated spaces have a reduced probability of being sites of random encounters [52].

\section{Introduction of Case Studies}

Table 2 provides a general overview of the selected case studies, including schools' floor plan, some general properties and the year when schools were built.

Table 2. Introduction of samples.

Plan (Legend: Sunken Courtyards are Marked in Green,
Ground Yards in Yellow, Small Porches (Semi-Outdoor
Spaces) in Red, Classrooms in Brown, Grand Porches
(Semi-Outdoor Spaces of Schools) in Orange, and Interior
Corridors in Blue)

Imam Khomeini School is located on the southeastern side of the Masjed-Jameh of Yazd, next to the Chahar Souq and the Shahi Bazaar. This school belongs to the Qajar period, the construction of which was completed in 1824. Formerly, it was known as the Shahzadeh School and has three courtyards, including a ground floor yard, a lower courtyard (sunken courtyard), and a small courtyard on the northwest side, which was formerly used as a girls' school [60].

Ground floor of Imam Khomeini school retrieved from Yazd Cultural Heritage Office.

One of the famous buildings of Yazd is the Markar complex, which includes a school, an
orphanage, and a clock tower. The school was built in 1934 in the first Pahlavi period, in
a modern style and completely different from the traditional schools of Yazd. Indeed, it
is a clear manifestation of modern schools. The in-row pattern of classrooms, corridors,
and a new educational system are the features of this school [35].

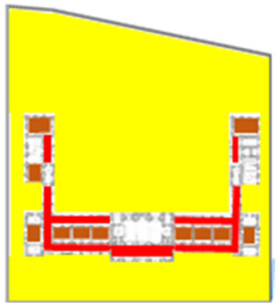

Iranshahr High School was built as one of the first modern schools in Yazd during the years 1937-1939 on the edge of the historical zone [61]. The school is located adjacent to the street with a small green garden, which marks the first change in the appearance of the buildings in the Pahlavi period compared to the traditional buildings [62]. 
Table 2. Cont

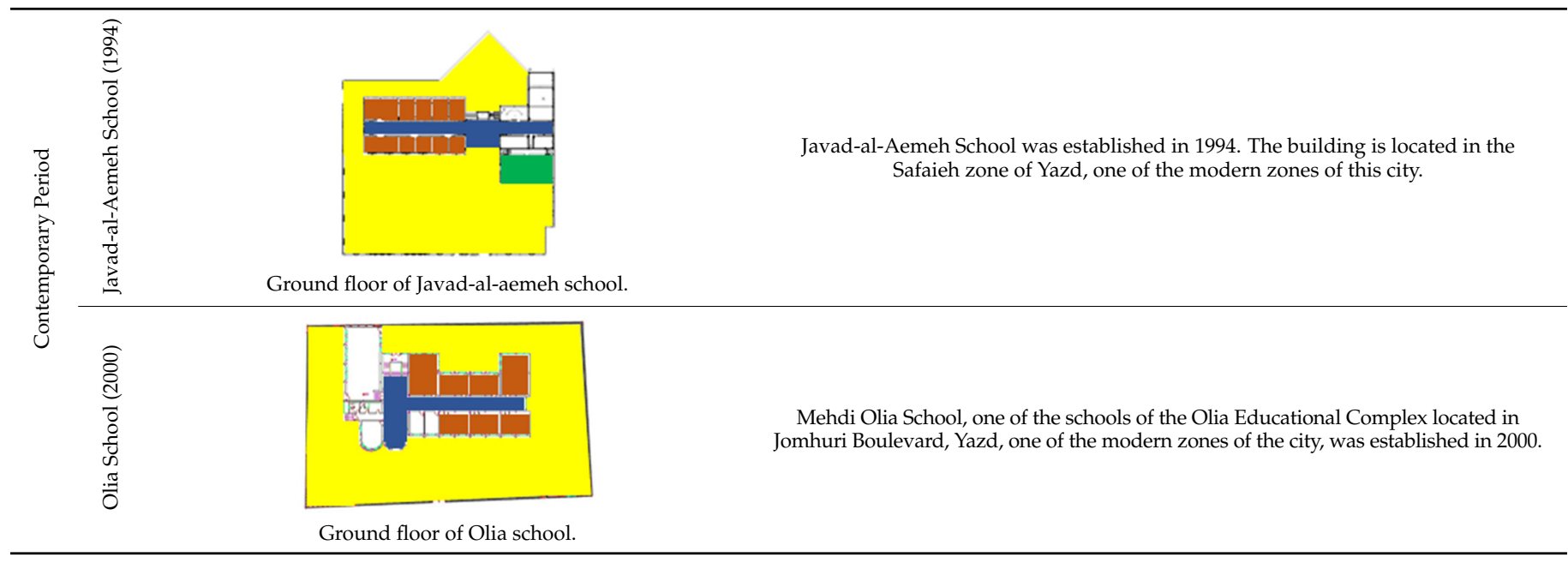

\section{Reviewing the Configuration and Function of Outdoor and Semi-Outdoor Spaces in the Mentioned Samples}

6.1. Macro-Scale: Comparative Study of Relationships among the Educational System of Schools and Location, Mutual Connections with the Neighborhood, and the Features and Functions of Outdoor and Semi-Outdoor Spaces of Schools

Khan and Imam Khomeini schools (case studies belonging to the traditional period) are both located at the center of the historical zone of Yazd near the bazaar and the main urban centers. Khan School is located near the Khan Bazaar and Khan Square, while Imam Khomeini School is adjunct to the Grand Bazaar and the Majed-Jameh. (Tables 3 and 4) The entrance of both schools is accessible from the Bazaar for passers-by and residents of the neighborhood. Outdoor and semi-outdoor spaces of these schools (porches or mentioned semi-outdoor spaces in Table 2) welcome neighborhood residents to hold religious lectures and ceremonies as a multi-functional space and are the center of educational-social activities. Moreover, neighborhood residents attend congregational prayers in these two schools on a daily basis.

Table 3. Macroscale: the relationship between outdoor and semi-outdoor spaces of the school and the neighborhood.

\begin{tabular}{ccccc}
\hline "ृ & Location (Images were Retrieved from Google & $\begin{array}{c}\text { Common Educational System and } \\
\text { Policies of Each Period in Iran }\end{array}$ & $\begin{array}{c}\text { Features and Functions of Outdoor and } \\
\text { Semi-Outdoor Space }\end{array}$ \\
\hline
\end{tabular}

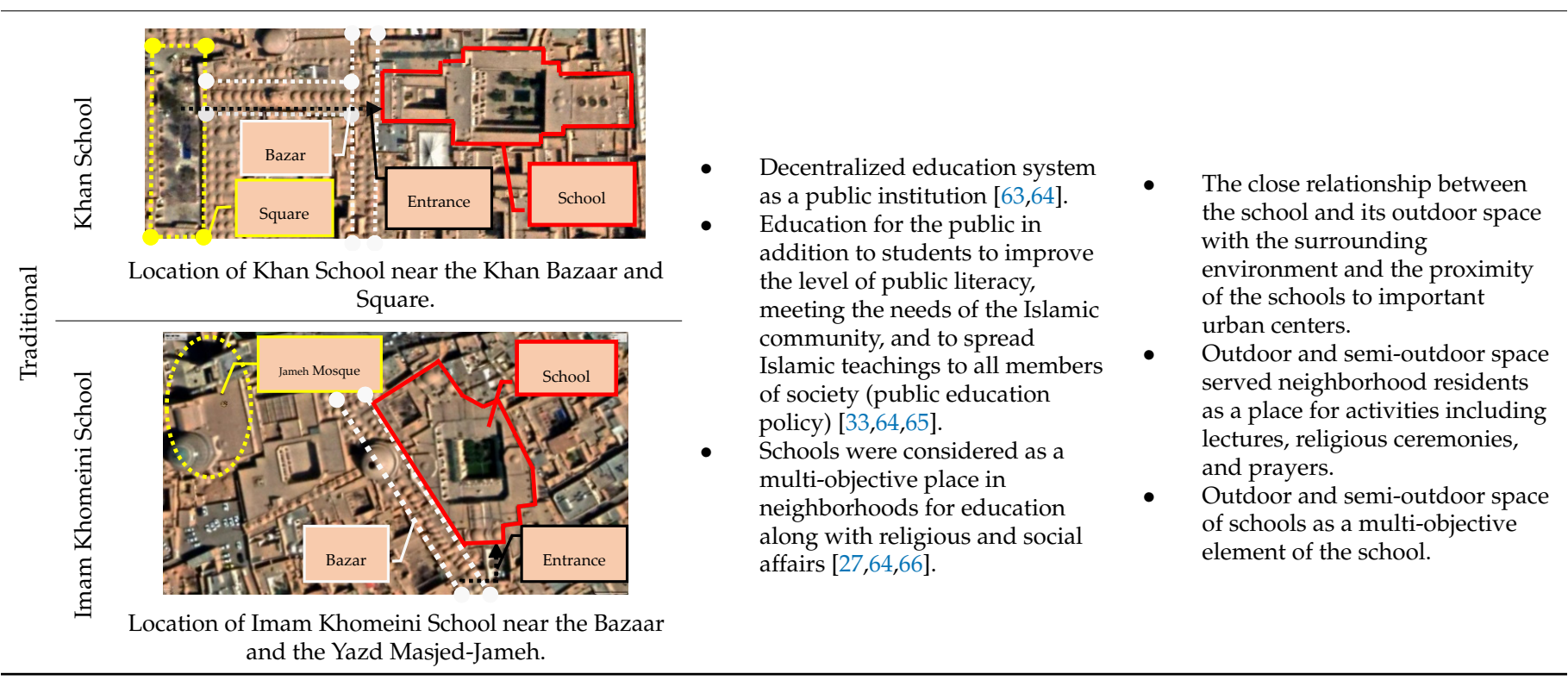


Table 3. Cont.

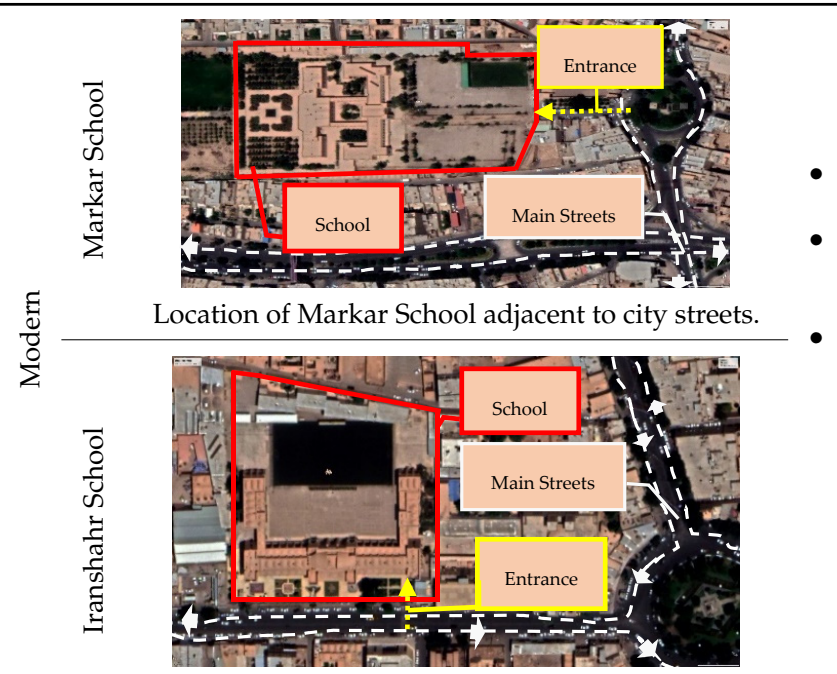

- $\quad$ Centralized and systematic educational system $[33,63]$.

- $\quad$ Education is dedicated to a certain number of students (only school students) [27].

The gap between the education process and religious and social affairs $[33,63]$.

Location of Iranshahr School adjacent to city streets.

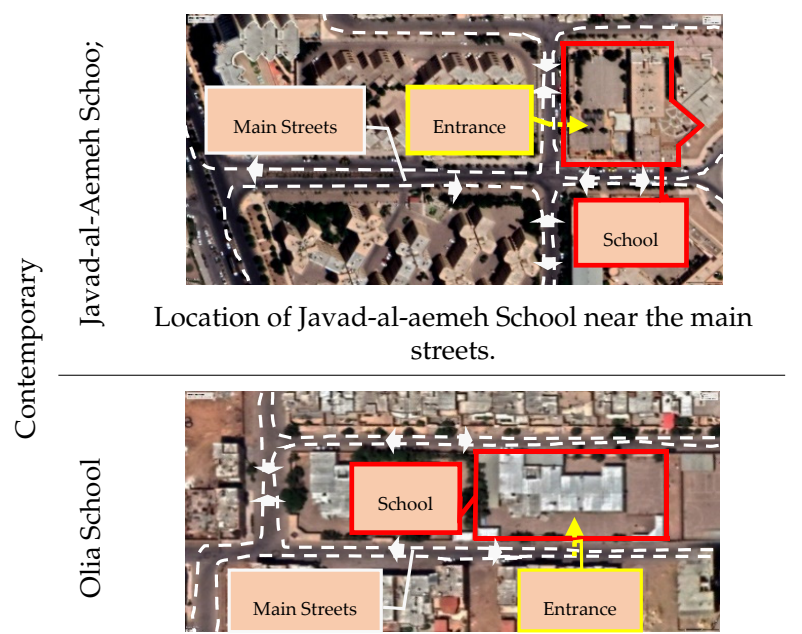

- $\quad$ Maintaining a centralized and systematic educational system [63].

- $\quad$ Education is dedicated to a certain number of students (only school students) [67].

- Religious orientation to some school activities such as changes in the content of some courses while maintaining centralized educational policies and teaching methods [63].
- Schools are not located near the important city centers. Additionally, the school's relationship with the adjacent environment is reduced.

- $\quad$ Absence of neighborhood residents in the outdoor space and school's porch to hold religious ceremonies and social communications.

- Lack of educational and religious lectures for neighborhood residents in outdoor and semi-outdoor spaces in schools.

Location of Olia School near the main streets.

Table 4. The entrance of the schools.

Entrance of Imam Khomeini School at the adjacent bazaar.


In Markar and Iranshahar schools, no activity taken part in by neighborhood residents was observed during the field study. Although these schools are located near a residential zone and have a sub-entrance from the neighborhood area, the main entrance of these schools is only accessible from urban streets. (Tables 3 and 4) In fact, schools are not receptive to the neighborhood residents. Disconnection with the surrounding environment and urban centers is significantly noticeable in Javad-al-Aemeh and Olia schools (contemporary schools). The entrance of these schools is only accessible from urban streets. (Tables 3 and 4) The outdoor spaces of these schools, which are surrounded by high walls and completely separated from the adjunct spaces, do not welcome the neighborhood residents. As a matter of fact, outdoor space in modern and contemporary schools, unlike the traditional period, does not play educational, social, and religious roles for the neighborhood residents; thus, the schools are not known as a public social place.

\subsection{Median Scale: Reviewing the Configuration and Spatial Settings of Schools' Outdoor and Semi-Outdoor Space}

6.2.1. Comparative Study of the Relationship between Outdoor Space of Schools and Semi-Outdoor Space, Indoor Space and Classrooms (Evaluation of Step Depth Index of Spaces from Outdoor Space) and Assessing the Possibility of Holding Classes in Porches and Courtyards

In this section, the step depth index of school spaces is investigated from the outdoor space. This section aims at comparatively studying the degree of the relationship between the outdoor space of schools in each period and other spaces, especially spaces in which the students' education is performed, such as classrooms. In this way, we tried to assess the possibility or impossibility of holding classrooms in outdoor and semi-outdoor spaces (flexibility or inflexibility of classes); i.e., the integration of indoor classrooms with outdoor and semi-outdoor spaces.

Studying the spatial configuration of Khan and Imam Khomeini schools indicates that in the traditional schools of Yazd, educational spaces such as classes and schools are aligned with the porches and courtyards so that there is a strong relationship and fluidity between outdoor space and educational spaces (Table 5). This feature of the spatial organization of traditional schools makes the educational spaces flexible and creates a strong bond between the semi-outdoor (porches) and outdoor spaces and indoor educational spaces. The existence of porches, classes, and other spaces surrounding the yard (central courtyard pattern) suggests the significant importance of the yard and the urgent need for a great connection between the yard and other spaces.

Table 5. Median scale: Step depth from main outdoor space. from the central outdoor space of the schools, respectively.

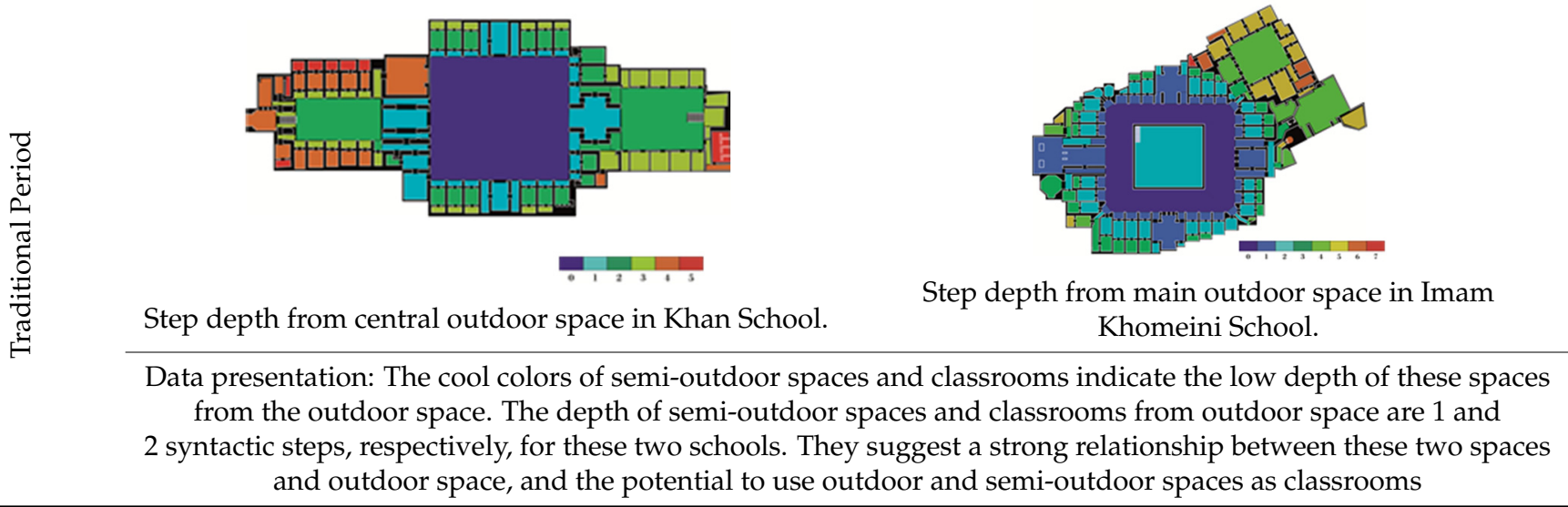


Table 5. Cont.

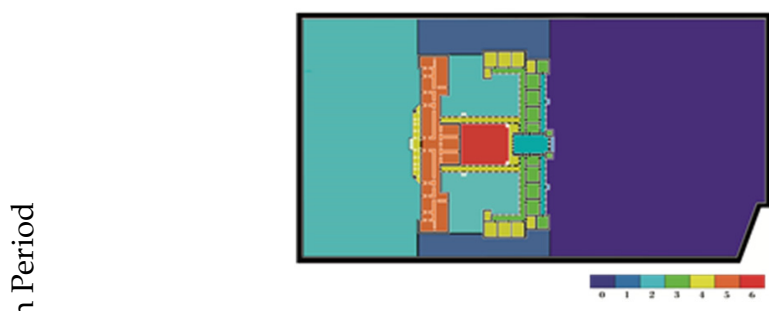

Step depth from main outdoor space in Markar School

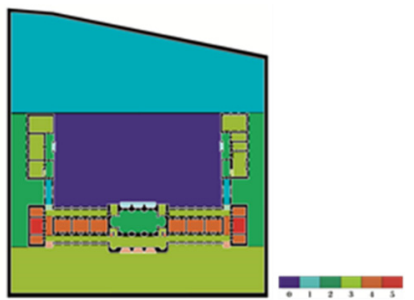

Step depth from main outdoor space in Iranshahr School.

Data presentation: The depth of the semi-outdoor space from the main outdoor space of Markar and Iranshahr schools is 2 and 3 syntactic steps, respectively. The greater depth of these spaces compared to traditional schools is due to multi-story buildings, i.e., the outdoor and semi-outdoor spaces are not placed on the same floor. The depth of the classrooms from the outdoor space in Markar and Iranshahr schools is 3 and 4 syntactic steps, respectively.

This suggests a weaker relationship between these two spaces in comparison with the traditional schools.

Therefore, outdoor space can no longer be integrated with the semi-outdoor space and classrooms due to the higher depth of outdoor space from semi-outdoor space and classrooms in these schools.

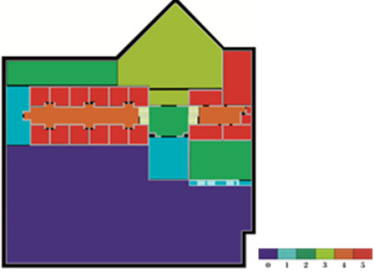

Step depth from main outdoor space in Javad-al-Aemeh School.

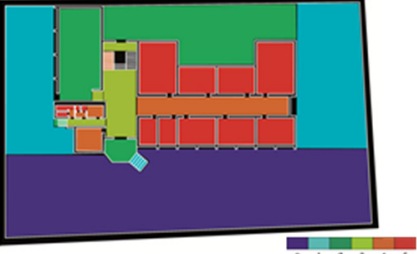

Step depth from main outdoor space in Olia School.

Data presentation: These schools do not have a semi-outdoor space, so outdoor and indoor space is connected through the entrance. The depth of the classrooms from the main outdoor space in these schools is 5 syntactic steps, which is greater than that of the traditional and modern schools. The red color of classes denotes the high depth of these two spaces and the lack of relationship between them. Therefore, in these schools, like the modern period schools, it is not possible to integrate the outdoor space into the classrooms due to the lack of relationship and flexibility.

In Markar and Iranshahr schools, several changes are found in terms of the spatial organization of schools compared to the traditional spatial patterns. Although an attempt has been made to preserve the central courtyard pattern by presenting a U-shaped model in the design of these schools, indoor spaces are surrounded by outdoor spaces. In addition, in these schools, the semi-outdoor spaces and porches have become linear and corridorshaped rather than separated porches for each classroom around a central courtyard. These changes in the spatial configuration of schools have weakened the connection between the outdoor spaces and semi-outdoor space and classrooms compared to the traditional schools (Table 5). Changes in the spatial configuration of schools can be seen more seriously in Javad-al-Aemeh and Olia schools. In these schools, the central courtyard pattern is eliminated and the indoor space is surrounded by outdoor space. Moreover, in these schools, the porches are replaced by indoor corridors to provide access and connection between outdoor and indoor spaces. These changes in the spatial configuration of schools caused a gap between classrooms and outdoor space (Table 5).

6.2.2. Comparative Study of Co-Presence Potential of Schools' Outdoor Space and Their Role in Organizing Access and Communication (Comparison of the Integration Index of the Outdoor Space of Schools)

This section aims at evaluating the role of the outdoor spaces of selected schools in organizing accessibility and circulation, and also, to examine the potential of co-presence in schools' outdoor space through the integration index of space syntax (Table 6). 
Changes in the form and configuration of schools in Yazd during different periods affected the role of outdoor space in organizing access and circulation within the school and the level of their co-presence potential (Table 6).The study of the integration index in the schools of different periods in Yazd shows that the integration value in the schools of the traditional period is 2.8 , which has decreased to about 1.5 in the modern schools and 0.9 in the contemporary schools (Figure 4). According to these results, outdoor and semioutdoor spaces in the traditional schools play the most important role in organizing the circulation and accessibility of these schools as the linking center of the complex (Table 6). Consequently, it has a high co-presence potential to be the main place for social interactions between students. In modern schools, the role of semi-outdoor corridors and public halls is significant in providing access, while the potential for outdoor space co-presence is decreased compared to the traditional schools (Table 6). Although in Iranshahr School, the central outdoor space along the corridors and the public hall play a role in organizing access, the yard of this school is no longer the only linking center of the complex. In the contemporary schools, there are indoor corridors that have the role of organizing the school circulation (Table 6). Therefore, the co-presence potential of outdoor space in these schools has been significantly reduced (Figure 4).

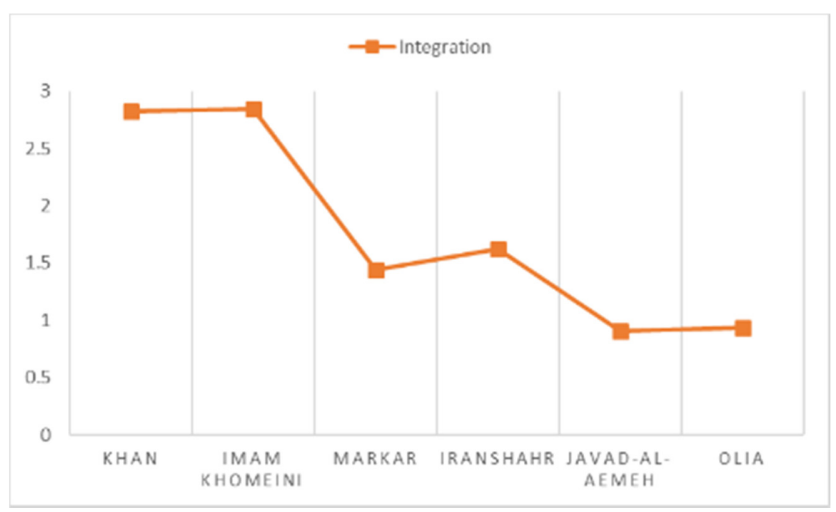

Figure 4. Comparing the integration values of the main outdoor spaces of schools: The average integration value of the main outdoor space has declined significantly from the traditional to the contemporary period.

Table 6. Median scale: the integration value of school spaces.

Convex map analysis: integration value
(Legend: The color spectrum from red to dark blue indicates the highest to lowest integration values of the spaces,
respectively.)
Graphic map of the integration value of spaces in
Khan School.
Data presentation: The red color of the outdoor space of Khan and Imam Khomeini schools indicates the high
integration value of outdoor space in these schools and thus their high potential for co-presence. Outdoor and
semi-outdoor spaces have the highest value of integration in the schools of this period, stating the significant role of
these spaces in organizing school accessibility and circulation, and consequently, their high potential for co-presence.


Table 6. Cont.
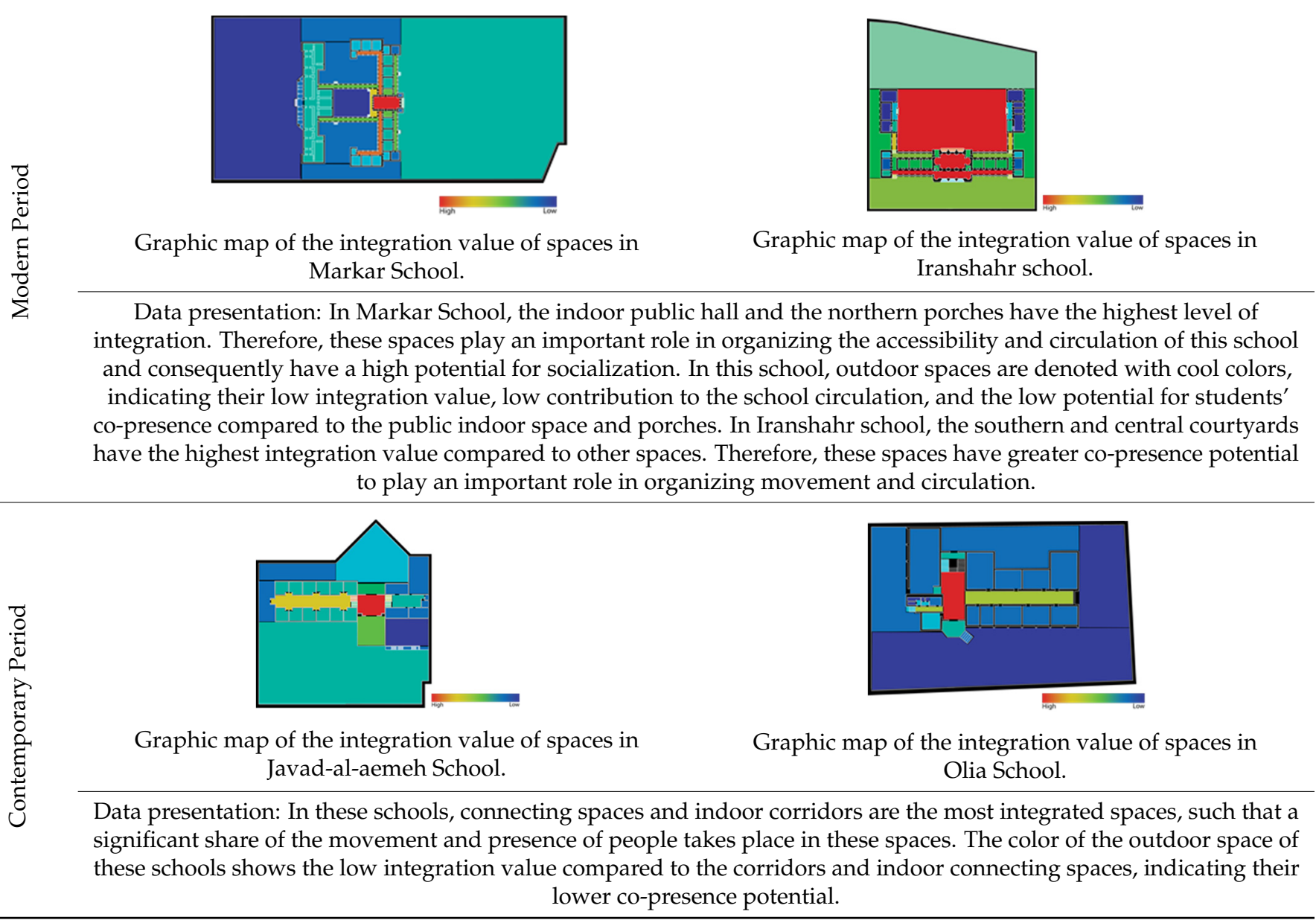

6.3. Micro Scale: The Role of the Outdoor and Semi-Outdoor Space of Schools According to the Common Teaching Methods in Each Education System

This section aims at the comparative study of the educational function of schools' outdoor space in terms of common teaching methods of the educational system to investigate the impact of teaching methods and educational policies on the application of schools' outdoor space.

Observations in the Khan and Imam Khomeini schools reveal that the educational spaces in these schools are not limited to classes and semi-outdoor spaces (such as porches) and central courtyards are also used to hold educational classes and play an educational role. In Markar and Iranshahr schools, observations show that the outdoor space is used only during break times. Additionally, these results show that the education process is performed regularly according to the curriculum only through the classrooms designated for different age groups. This is exactly the case in Javad-al-Aemeh and Olia schools. Field study in these schools showed that the outdoor space is used only during break times in these schools, like the modern period. Additionally, the education process is performed according to a certain curriculum only through the classrooms designated for each age group (Table 7). 
Table 7. Microscale: Functions of outdoor and semi-outdoor spaces of schools according to the educational policy and teaching method in each educational system. (Legend: Spaces used for holding classes are highlighted in green).

\begin{tabular}{ccccc}
\hline $\overrightarrow{0}$ & \multirow{Z}{0}{} & $\begin{array}{c}\text { The outdoor or semi-outdoor space } \\
\text { of schools }\end{array}$ & $\begin{array}{c}\text { Educational space according to the } \\
\text { teaching method }\end{array}$ & $\begin{array}{c}\text { Educational system and function of } \\
\text { outdoor and semi-outdoor space }\end{array}$ \\
\hline
\end{tabular}

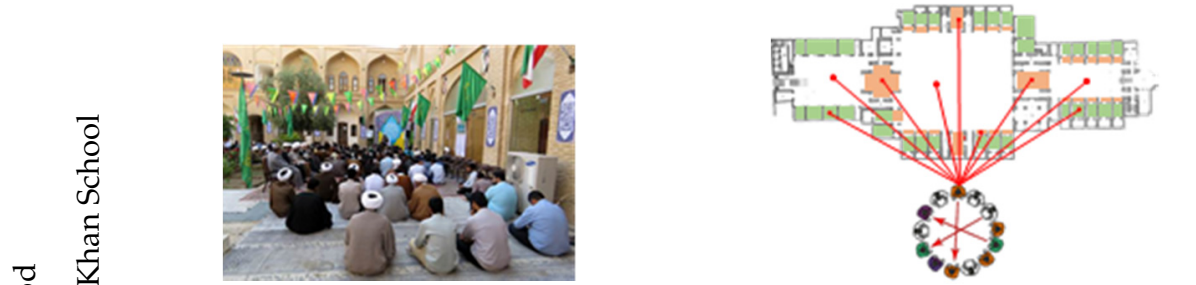

Discussion loop in the middle courtyard of Khan School.

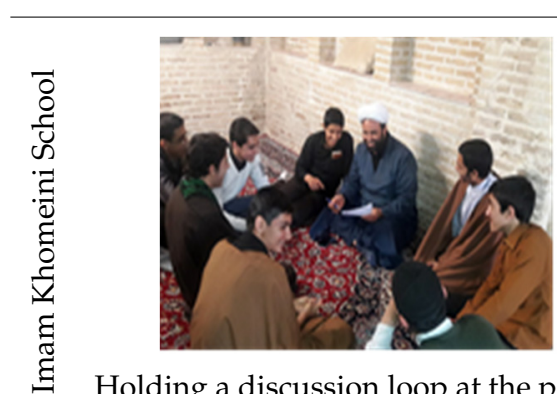

Holding a discussion loop at the porch of Imam Khomeini School.

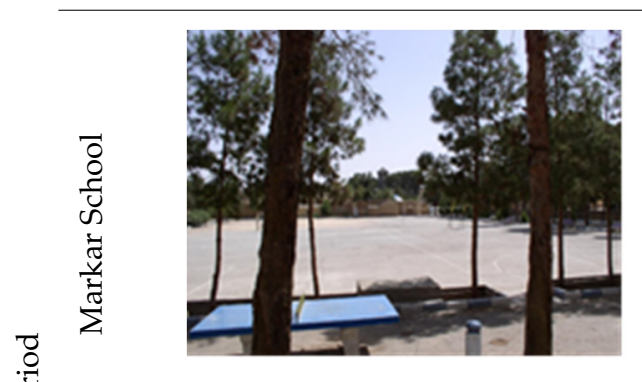

Empty yard of students during educational hours Markar School.

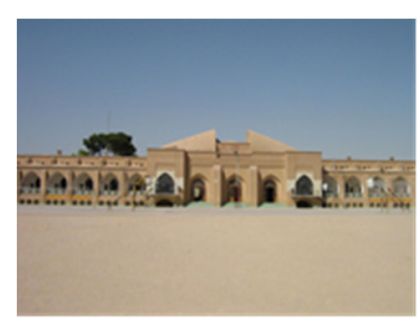

Empty yard of students during educational hours.
Location of discussion loop in Khan

School including outdoor, semi-outdoor, and indoor spaces.

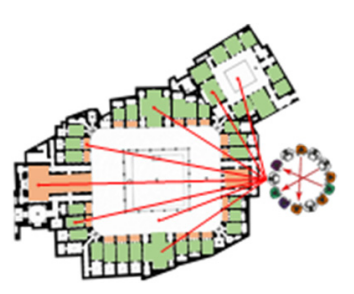
Khomeini School including outdoor, semi-outdoor, and indoor spaces.

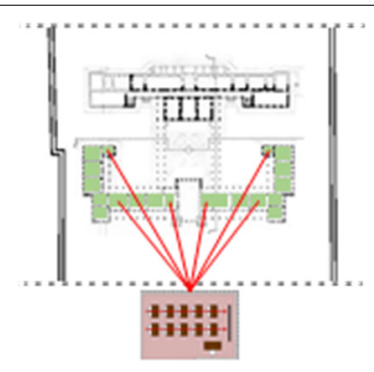

Education process limited to classrooms at Markar School.

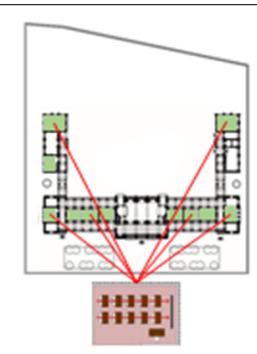

Education process limited to classrooms at Iranshahr School.
Discussion loop location in Imam
- $\quad$ Teaching system and method:

- The process of education based on discussion between individuals in the form of a loop model;

- The possibility of including other people, such as students of other levels and the public, in the educational loop.

- Outdoor and semi-outdoor space function:

- Active educational role of outdoor and semi-outdoor spaces such as the central courtyard and porches and the formation of educational circles in these spaces.

- $\quad$ Teaching system and method:

- Presentation of a lesson by a specific teacher based on a pre-determined curriculum and without the active participation of students;

- Fixed curriculum based on different age groups.

- Outdoor and semi-outdoor space function:

- Using the schoolyard only during break times;

- Lack of outdoor and semi-outdoor spaces application for holding classes, so the education process is limited to classrooms assigned to a defined age group. 
Table 7. Cont.

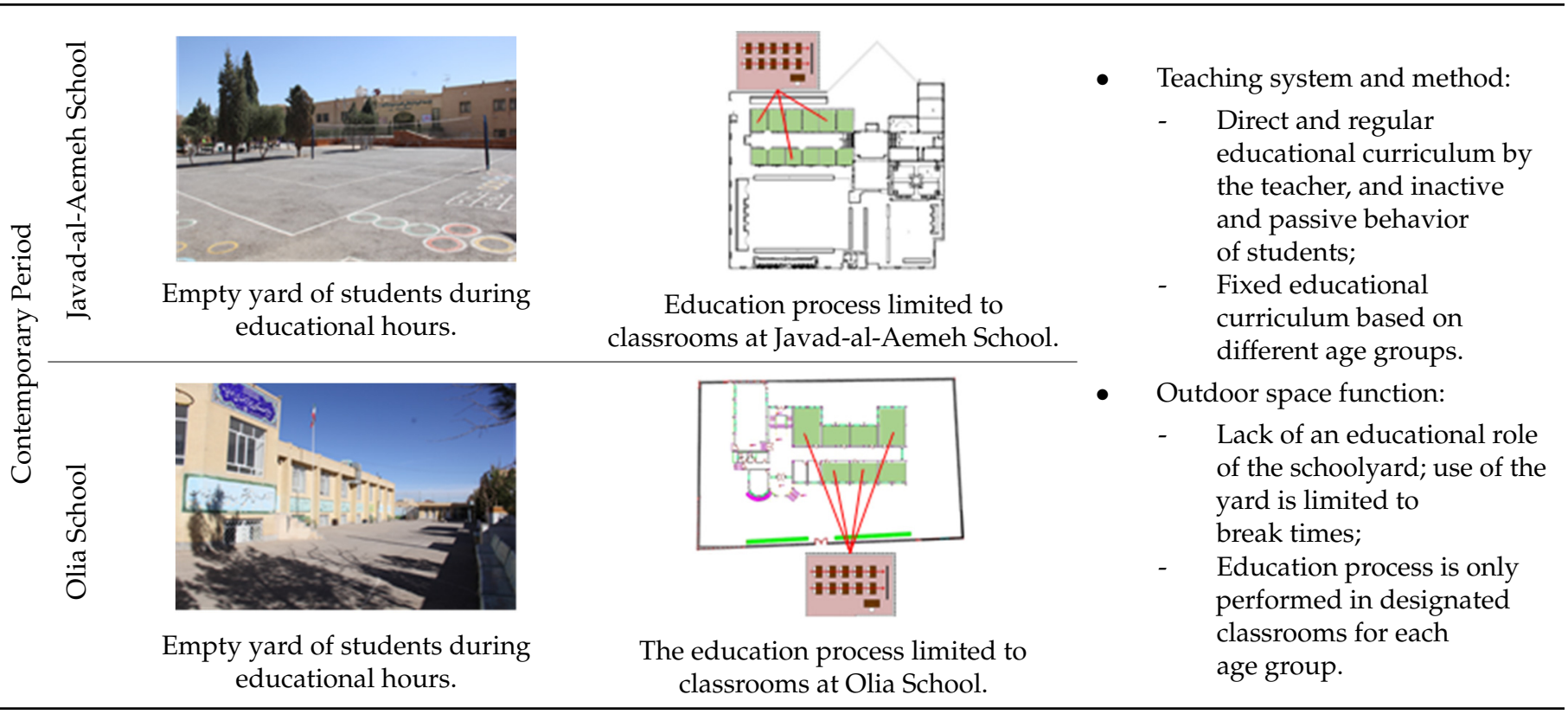

\subsection{Comparative Study of the Schools' Configuration and Their Educational Policies}

Table 8 summarizes the trend in the configuration developments and functions of outdoor and semi-outdoor spaces in schools of Yazd and their governing educational system.

Table 8. Summary of the spatial configuration, educational policies, and functions of outdoor spaces in the six case studies.

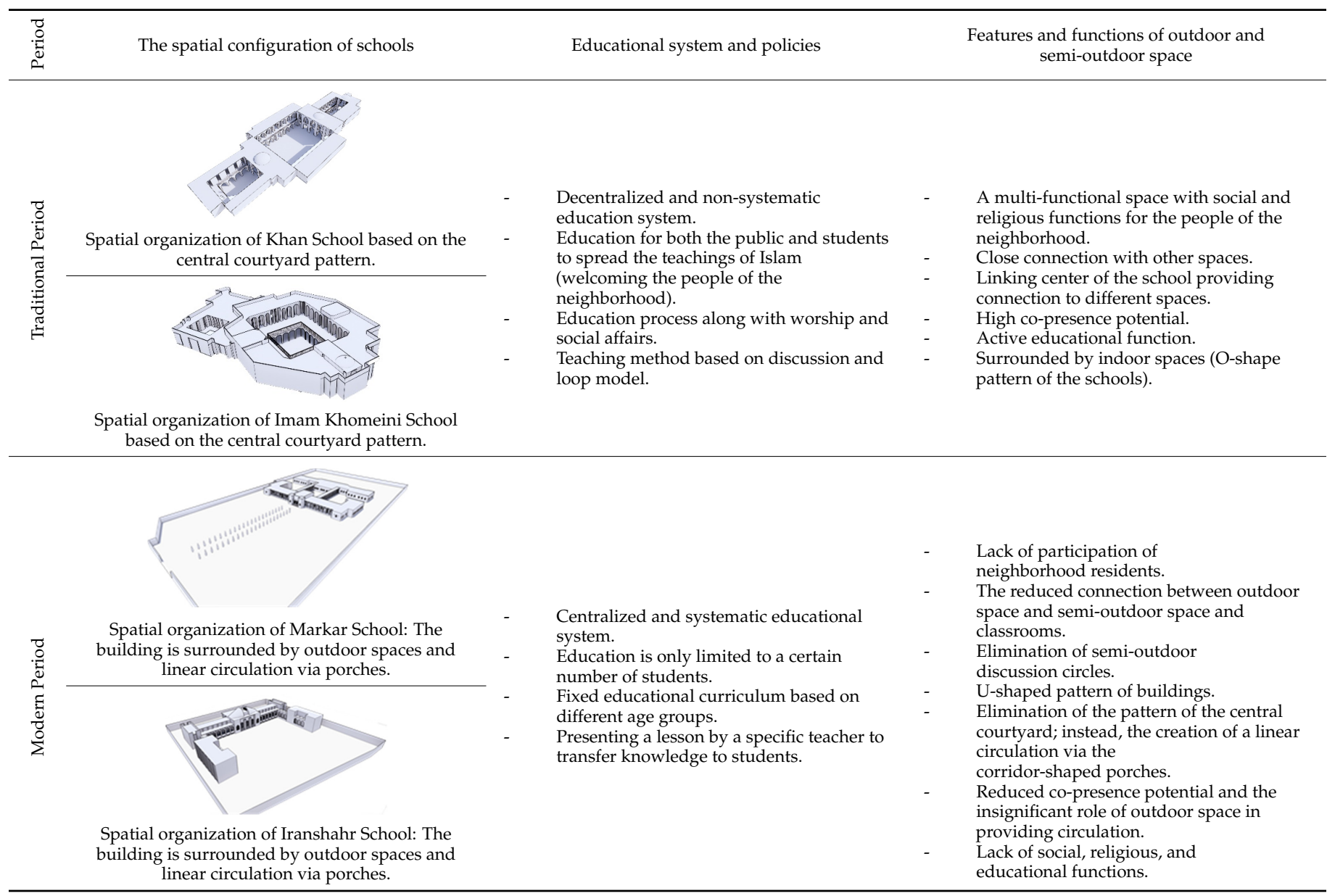


Table 8. Cont.

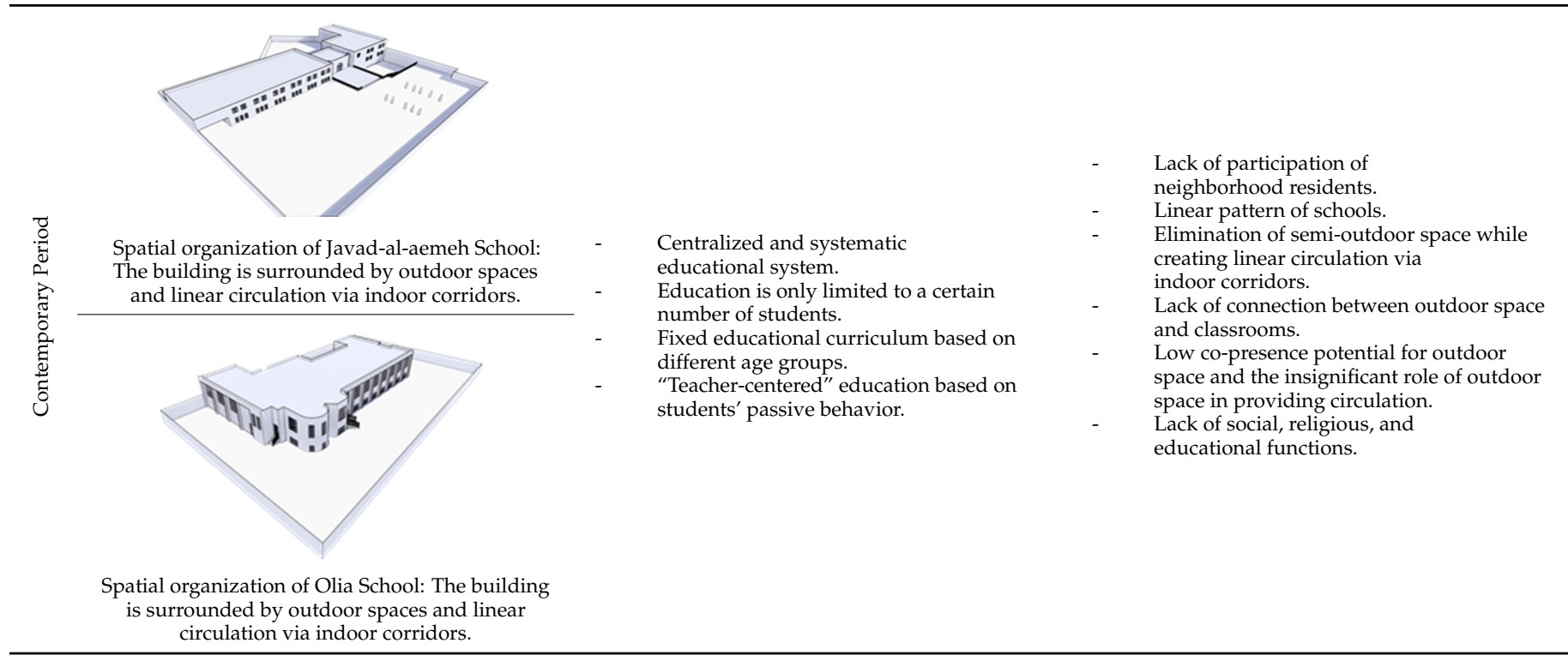

\section{Discussion}

The results and data presented in the previous section will determine whether our hypotheses are supported. As mentioned previously, the field study was performed in school sites to observe the functions of Yazd schools' outdoor spaces in six case studies, belonging to three different periods. In addition, space syntax analysis applying the DepthmapX program was employed to assess the spatial configuration of the case studies. The following is a review of results obtained from both analyses to indicate whether our hypotheses are supported.

Hypothesis 1 (H1). There is a direct relationship between the educational policies governing in schools and the functions served by the outdoor space of the schools to neighborhood residents.

The data seem to support this hypothesis. During the field study in the schools, it was clearly observed that Khan and Imam Khomeini schools welcomed the neighborhood residents to attend congregational prayers and religious ceremonies, as well as to join the discussion loops formed in the outdoor and semi-outdoor space of the schools (Table 3). This function of the outdoor and semi-outdoor space of these schools can be attributed to their governing educational policies, as the main purposes of these schools in this education system is not only to educate students but also to spread the teachings of Islam to all members of the society. Thus, residents are free to enter the schools and ask their religious questions from teachers and mullahs in the schools. As a matter of fact, the idea of a community school, considering school space as an urban space and active social center, was obvious in traditional Iranian schools $[66,68]$. The reason is that following the educational policies in schools of this period, the school space is not limited to students but teaches all people and welcomes them to hold prayers, holds religious lectures to promote the Shiite religion, and eliminates people's ambiguities in terms of religious issues. In general, the school addresses the promotion of the level of knowledge and awareness of the people $[69,70]$. The location of schools in the Islamic era near social areas including mosques, markets, and squares highlights the social role of schools [71].

On the other hand, in Markar and Iranshahr schools (modern schools), and Jacad-alAemeh and Olia schools (contemporary schools), neighborhood residents are not allowed to enter the schools and no social or religious events including residents are held in these schools (Table 3). It seems that this feature (lack of welcoming the neighborhood residents) is related to the current educational policies in these schools, such as the centralization of 
the educational process and the right of education only for the students. Therefore, no role is considered for today's school as a social center to teach its neighbors [67].

Hypothesis 2 (H2). The degree of the relationship between the outdoor space of schools and other spaces, semi-outdoor spaces and classrooms in particular, has diminished in Yazd schools over time.

This hypothesis is about the topological location of schools' outdoor spaces in schools' architectural plans, which was tested by measuring the step depth index of spaces from outdoor spaces, which is an indication of the distance between one space and every other space in a plan, through the space syntax analysis. The hypothesis is supported by the analysis, as in the traditional case studies, the depth of semi-outdoor spaces and classrooms from outdoor space are 1 and 2 syntactic steps, respectively. On the other hand, the depth of the semi-outdoor space from the main outdoor space of Markar and Iranshahr schools is 2 and 3 syntactic steps, respectively. Moreover, the depth of the classrooms from the outdoor space in Markar and Iranshahr schools is 3 and 4 syntactic steps, respectively. In addition, the depth of the classrooms from the main outdoor space in Javad-al-Aemeh and Olia schools is 5 syntactic steps, which is greater than that of the traditional and modern schools (Table 5).

Hypothesis 3 (H3). The possibility of being the site of encounter has decreased in the outdoor spaces of Yazd schools over time.

This hypothesis is about the co-presence potential of schools' outdoor spaces for facilitating movements and encounters, which was examined by measuring the integration index of schools' outdoor spaces, which is an indication of the likelihood of being a site of encounter in a space, through the space syntax analysis. The hypothesis is supported by the analysis, as the ratio of outdoor space average integration in Khan and Imam Khomeini schools is 2.82 and 2.84, respectively. Nevertheless, the figure for Markar, Iranshahr, Javadal-Aemeh, and Olia is $1.44,1.62,0.91$, and 0.94 , respectively, indicating that the co-presence potential of outdoor space in Yazd schools has significantly reduced over the three periods (Table 6).

Hypothesis 4 (H4). There is a direct relationship between the governing educational policies in the schools, i.e., teaching methods and course contents, and the functions of the outdoor space of the schools.

The data seem to support this hypothesis as well. During the field study, it was observed that in the schools of the traditional period, in which in the spatial configuration of the schools there are direct and strong relationships among classrooms, semi-outdoor spaces, and outdoor spaces, and the educational policies include teaching methods based on discussion and the loop system, and religious education content is implemented, outdoor and semi-outdoor spaces are frequently used for holding classes and forming discussion circles (Table 7). This is also confirmed by some other scholars. According to these scholars $[31,33,36,66,69]$, in Iranian traditional schools, it is possible to hold discussion loops, both formally and informally, in all school spaces, small or large, and outdoor or indoor spaces. Furthermore, in many cases, these sessions extend to the outdoor space to utilize the yard for the education process. The use of outdoor and semi-outdoor spaces for education arose from three main features of the traditional education system: (1) the discussion-based teaching method, (2) the usefulness of the educational content for all levels of advanced, intermediate, and even elementary and public groups, and (3) the strong bond between education and religion [29,31].

However, observations in the case studies belonging to modern and contemporary case studies reveal that the schools' outdoor spaces are only used during break times, and are not used for holding classes. It seems that in both modern and contemporary schools, the education process can only be conducted through defined classes. (Table 7) In 
fact, the research results reflect the fact that the new education process in Iranian modern and contemporary schools takes place mainly inside the building, such that outdoor and semi-outdoor spaces have no significant impact $[27,31,36]$, which is due to the two features of the classical educational idea. First, the teaching methods in this educational system have an inherent reliance on the existence of absolute discipline. In other words, because there is less concern about disturbing factors such as noises, miscellaneous movements, and attractive objects, the classrooms provide the most appropriate conditions for direct, regular, and uniform education based on students' inactive and passive behavior [36,72]. Second, the teaching and learning process is based on the passive presence of students in the education process, i.e., a lesson is taught only by the teacher $[27,36]$.

Hypothesis 5 (H5). There is a direct relationship between the evolution of schools' outdoor space layouts and changes in educational policies in Yazd schools over time.

In general, the results of the present paper show that in the traditional schools of Yazd, the configuration of the schools of this period has an active and dynamic function of the courtyard by presenting the organization of the central courtyard, so that the courtyard is placed at the center of the school building with a close connection to the porches and classrooms, and plays an important role in facilitating movements. Nevertheless, the configuration of modern and contemporary schools has changed in comparison with traditional schools. The new architectural model of schools is as follows: surrounding the school building with outdoor spaces, rows of classrooms on one or both sides of a corridor, and weakening the connection between outdoor and indoor spaces. However, it is of note that although modern and contemporary case studies have some features in common, they are not same. In the modern case studies, although the pattern of the courtyard is eliminated, the school buildings have a U-shape plan. In addition, the semi-outdoor spaces play an important role in facilitating movements. Nonetheless, in the contemporary schools, there is no semi-outdoor space in the schools anymore, and the movements are facilitated by indoor corridors. In addition, the school buildings have a linear plan. (Table 8) As can be seen in the spatial configuration of Yazd schools, the physical changes in the modern schools are less noticeable than in the contemporary schools because the spatial organization of schools has undergone a fundamental change during the contemporary period. In the modern period, schools were built during the early Cultural Revolution in Iran, and regarding the long distance of Yazd as a traditional city from the Iran capital, these schools have undergone less change in architecture. Therefore, the traditional and domestic architectural style of Yazd was considered in the building of schools. These buildings have an intermediate architecture, meaning that they are not built entirely according to traditional architecture nor were they inspired by the patterns of European schools at the time [61].

Overall, although the results suggest a relationship between the evolution of schools' outdoor space layouts and changes in educational policies in Yazd schools over time, and a number of studies conducted on Iranian schools $[27,31,33,34,36]$ concluded that the alterations in the educational system have resulted in changes in the spatial configuration of schools, it is not straightforward to explicitly express the proposition that the changes in the spatial organization of Yazd schools is fully attributable to the modern educational system, since the other socio-cultural aspects that might have been involved in this issue are not considered in the present paper. Therefore, this hypothesis could only be partially supported by the current research findings.

\section{Conclusions}

Nowadays, the importance of education and educational spaces is significantly considered. Combining space syntax analysis and the field study method, this research, based on a case study, proposed five hypotheses and focused on analyzing the functions and spatial layouts of schools' outdoor spaces in the historic city of Yazd within three defined periods, and studied their changes in relation to their educational system governing in the schools. 
Before reviewing the findings, it is important to reiterate the limitations and strengths of the research. In addition to bridging the knowledge gap about the evolution of schools in Yazd, this paper has two significant dimensions. First, it is one of only a small group of papers on the evolution of Iranian schools' layouts using both quantitative and qualitative research methods. Moreover, the field study for observing the functions of the outdoor spaces of schools is noteworthy for its relatively extended time period. Notwithstanding these two features, as the focus is on typology and the functions of schools' outdoor spaces based on the evolution of the educational system, this paper is not concerned with some other cross-sectional variations, contextual issues, and environmental factors that might have been involved in the evolution of schools' spatial organization in Yazd, and cannot offer any direct evidence about environmental and socio-cultural conditions rather than governing educational policies in the schools. Based on the field study and space syntax analysis, the following findings were obtained:

i. There is a direct relationship between the educational policies governing in Yazd schools and the functions served by the outdoor space of the schools to neighborhood residents. As a matter of fact, observing the functions of outdoor and semi-outdoor spaces in Yazd schools shows that in the case studies belonging to the traditional period, the educational system of which is highly based on the religious content of the courses, the outdoor and semi-outdoor spaces welcome all the neighborhood residents and have active social functions. On the contrary, in the case studies belonging to the modern and contemporary periods, the educational systems of which rely on just educating students in the specific age groups, the outdoor space of the schools does not serve any function for residents and is not receptive to neighborhood residents.

ii. The degree of the relationship between the outdoor space of schools and other spaces, semi-outdoor spaces and classrooms in particular, has diminished in Yazd schools over time. While the depth of semi-outdoor spaces and classrooms from outdoor space are 1 and 2 syntactic steps in traditional case studies, respectively, the depth of the semi-outdoor space from the main outdoor space of Markar and Iranshahr schools is 2 and 3 syntactic steps, respectively. Moreover, the depth of the classrooms from the outdoor space in Markar and Iranshahr schools is 3 and 4 syntactic steps, respectively. In addition, the depth of the classrooms from the main outdoor space in Javad-al-Aemeh and Olia schools is 5 syntactic steps, which is greater than that of the traditional and modern schools.

iii. The possibility of being the site of encounter has decreased in the outdoor space of Yazd schools over time. The ratio of outdoor space average integration in Khan and Imam Khomeini schools is 2.82 and 2.84, respectively. Nevertheless, the figure for Markar, Iranshahr, Javad-al-Aemeh, and Olia is 1.44, 1.62, 0.91, and 0.94, respectively, indicating that the co-presence potential of outdoor space in Yazd schools has significantly reduced over the three period.

iv. There is a direct relationship between the governing educational policies in the schools, i.e., teaching methods and course contents, and the functions of the outdoor space of Yazd schools. During the field study, it was observed that in the schools of the traditional period, in which in the configuration of the schools, there are direct and strong relationships among classrooms, semi-outdoor spaces, and outdoor spaces, the educational policies include teaching methods based on discussion and the loop system, and religious education content is implemented, outdoor and semi-outdoor spaces are regularly used for holding classes and forming discussion circles. However, observations in modern and contemporary case studies, the educational systems of which mainly rely on transferring knowledge from teachers to students based on the passive role of students in the learning process, as well as an extremely fixed curriculum, revealed that the schools' outdoor spaces were only used during break times, and were not used for holding classes. It seems that the new education system believes that since there is more concern about disturbing factors such as noise and 
miscellaneous movements in the outdoor space of the schools, the classrooms provide the most appropriate conditions for direct, regular, and uniform education.

v. With regard to the spatial layouts of the six case studies, overall, in the spatial configuration of the traditional schools in Yazd, the courtyard is surrounded by the indoor spaces, and outdoor and semi-outdoor spaces play an important role in providing accessibility as the main site of the encounters. Nevertheless, in the modern case studies, the courtyard pattern is eliminated, the school buildings form a U-shape plan and are surrounded by the outdoor spaces, and the semi-outdoor spaces are formed in a corridor shape. Although in the modern case studies, the outdoor space of the schools is no longer the main site of encounters in the schools, semi-outdoor spaces are still the main spaces providing accessibility. Finally, changes in the contemporary case studies, compared to the modern cases, are more apparent. The school buildings have a linear pattern. In addition, the semi-outdoor spaces are eliminated and replaced by indoor linear corridors, which are the main site of encounters in the schools. As a matter of fact, the significance of the outdoor space in the schools of the contemporary period has diminished considerably, in comparison to the schools of the two other periods mentioned in the paper. However, despite the fact that the computational and the field study evidence suggest that there is a relationship between the evolution of schools' outdoor space layouts and changes in the educational policies in Yazd schools over time, as mentioned previously, since the current paper does not consider other cross-sectional variations involved in the issue, it cannot affirm that the changes in the spatial configuration of Yazd schools can be entirely attributed to the evolution of the education system in Yazd schools. Studying other variations that might have affected the evolution of school layout in Yazd could put forward important questions for further research: how is the evolution of the spatial configuration of the schools affected by other variations, such as social and cultural changes in a society?

Author Contributions: Conceptualization, F.F.T. and H.M.A.; methodology, F.F.T.; software, F.F.T.; validation, F.F.T. and H.M.A.; formal analysis, F.F.T.; investigation, F.F.T.; resources, F.F.T.; data curation, F.F.T.; writing-original draft preparation, F.F.T.; writing-review and editing, F.F.T. and H.M.A.; visualization, F.F.T. All authors have read and agreed to the published version of the manuscript.

Funding: This research received no external funding.

Conflicts of Interest: We declare no conflict of interest.

\section{References}

1. Gifford, R.; Steg, L.; Reser, J. Environmental Psychology. In IAAP Handbook of Applied Psychology; John Wiley \& Sons: Hoboken, NJ, USA, 2011; pp. 440-470.

2. McLane, Y. Choreographing collaborative academic experiences: The 'quiet building' and the 'airport lounge'. In Proceedings of the10th International Space Syntax Symposium, London, UK, 13-17 July 2015.

3. Schneider, M. Do School Facilities Affect Academic Outcomes? National Clearing House for Educational Facilities: Washington, DC, USA, 2002.

4. Mortazavi, S. Educational Facilities from a Psychological Perspective; Publications of the School Renovation Organization: Tehran, Iran, 1997.

5. Mygind, E. A comparison of childrens' statements about social relations and teaching in the classroom and in the outdoor environment. J. Adventure Educ. Outdoor Learn. 2009, 9, 151-169. [CrossRef]

6. Fägerstam, E. High school teachers' experience of the educational potential of outdoor teaching and learning. J. Adventure Educ. Outdoor Learn. 2014, 14, 56-81. [CrossRef]

7. Broda, H.W. Schoolyard-Enhanced Learning: Using the Outdoors as an Instructional Tool, K-8; Stenhouse Publishers: Portsmouth, NH, USA, 2007.

8. Rickinson, M.; Dillon, J.; Teamey, K.; Morris, M.; Choi, M.Y.; Sanders, D.; Benefield, P. A Review of Research on Outdoor Learning; National Foundation for Educational Research and King's College London: London, UK, 2004; Available online: https://www.academia.edu/288162/A_Review_of_Research_on_Outdoor_Learning (accessed on 6 October 2020).

9. Chillman, B. Do School Grounds Have a Value as an Educational Resource in the Secondary Sector? Learning Through Landscapes: Winchester, UK; Sussex University: Brighton, UK, 2003. 
10. Hartmeyer, R.; Mygind, E. A Retrospective Study of Social Relations in a Danish Primary School Class Taught in 'Udeskole'. J. Adventure Educ. Outdoor Learn. 2016, 16, 78-89. [CrossRef]

11. Farhangh, M.; Fatemeh, M.; Somayeh, M. Recognition of the Role of Nature in Educational Spaces. J. Technol. Educ. 2009, 4, 37-46.

12. Mall, C.; Lauterbach, G.; Spengler, S.; Dettweiler, U.; Mess, F. Effects of Regular Classes in Outdoor Education Settings: A Systematic Review on Students' Learning, Social and Health Dimensions. Int. J. Environ. Res. Public Health $2017,14,485$.

13. Fägerstam, E.; Samuelsson, J. Learning arithmetic outdoors in junior high school-influence on performance and self-regulating skills. Educ. 2012, 42, 419-431. [CrossRef]

14. Initiative, B.S. Outdoor Classroom Users Guide. 2015. Available online: http:/ /schoolyards.org/pdf/OutdoorClassroomUsersGuide.pdf (accessed on 10 October 2020).

15. Education Development Center. Schoolyard Learning: The Impact of School Grounds. ERIC Clearinghouse. 2000. Available online: http:/ / www.schoolyards.org/pdf/Schoolyard\%20Learning-The\%20impact\%20of\%20School\%20Grounds.pdf (accessed on 11 October 2020).

16. Fägerstam, E. Space and Place: Perspectives on Outdoor Teaching and Learning. In Department of Studies in Behavioural Science; Linköping University Electronic Press: Linköping, Sweden, 2012; p. 100.

17. Fägerstam, E.; Blom, J. Learning biology and mathematics outdoors: Effects and attitudes in a Swedish high school context. J. Adventure Educ. Outdoor Learn. 2013, 13, 56-75. [CrossRef]

18. James, J.; Williams, T. School-Based Experiential Outdoor Education: A Neglected Necessity. J. Exp. Educ. 2017, 40, 58-71. [CrossRef]

19. Mozaffar, F.; Mirmoradi, S.S. Effective Use of Nature in Educational Spaces Design. Organ. Technol. Manag. Constr. Int. J. 2012, 4, 381-392. [CrossRef]

20. Dillon, J.; Ian, D. Learning in the Natural Environment: Review of Social and Economic Benefits and Barriers; Natural England Commissioned Reports 92; Natural England: York, UK, 2012.

21. Dillon, P.; Craft, A.; Best, P. Turning Peases West Inside Out: Flexible Educational Environments for Developing Possibilities and Pedagogies; Report for the Arts Council of England Creative Partnerships; publisher: County Durham, 2007.

22. Castelijns, J.; Vermeulen, M.; Kools, Q. Collective learning in primary schools and teacher education institutes. J. Educ. Chang. 2013, 14, 373-402. [CrossRef]

23. Ahmadpanah, M.; Soheili, S.; Jahangard, L.; Bajoghli, H.; Haghighi, M.; Holsboer-Trachsler, E.; Conrad, D.; Brand, S.; Keikhavandi, S. Cooperative Learning Improves Social Skills and Knowledge of Science Topics in Pre-adolescent Children in Iran. Br. J. Educ. Soc. Behav. Sci. 2014, 4, 1029-1037. [CrossRef]

24. Blumenfeld, P.C.; Kempler, T.M.; Krajcik, J.S. Motivation and Cognitive Engagement in Learning Environments. In The Cambridge Handbook of the Learning Sciences; Sawyer, R.K., Ed.; Cambridge University Press: New York, NY, USA, 2006 ; pp. 475-488.

25. Nichols, J.D.; Miller, R.B. Cooperative Learning and Student Motivation. Contemp. Educ. Psychol. 1994, 19, 167-178. [CrossRef]

26. Wentzel, K.R. Student Motivation in Middle School: The Role of Perceived Pedagogical Caring. J. Educ. Psychol. 1997, 89, 411. [CrossRef]

27. Tahersima, S.; Irani Behbahani, H.; Bazrafkan, K. Determining of educational role of Iranian school open spaces Regarding the comparative investigation on traditional vs. contemporary school (case studies: Chaharbagh, Darlolfonoun and Alborz schools). Iran Univ. Sci. Technol. 2015, 3, 55-67.

28. Stadler-Altmann, U. Indoors and Outdoors: Schoolyards as learning and playing opportunities. J. Phys. Educ. Sport 2021, 21, 553-559.

29. Isfahani, M. Methods of Education and Teaching in Seminaries; Qom Book Park: Qom, Iran, 2014.

30. Sadiq, I. Modern Persia and Her Educational System; Columbia University Press: New York, NY, USA, 1931.

31. Irvani, S. History of School Architecture in Iran. 2010. Available online: www.designshare.com (accessed on 25 September 2018).

32. Nasiri, M. A study of the evolution of the education system of semeniries in the Qajar and Pahlavi periods. Hoze 2009, 25, 195-278.

33. Sami Azar, A. The History of Iranian Schools Development; Organization for Development, Renovation and Equipping Schools of Iran: Teheran, Iran, 1997.

34. Khodabakhshi, S.; Foroutan, M.; Samiei, A. The Evolution of Space in Schools Architecture Based on the Role of Their Governing Educational system (Case Study: Sepahsalar School, Darolfunoon, and Alborz High school). Bagh-E Nazar 2016, 12, 61-74.

35. Alaghmand, S.; Salehi, S.; Mozaffar, F. A Comparative Study of Architecture and Content of Iran's Schools from the Traditional Era to the Modern Era. Mon. Sci. J. Bagh-E Nazar 2017, 14, 5-20.

36. Sami Azar, A. The concept and function of outdoor space in traditional and modern schools. Soffeh 2001, 10, 104-111.

37. Bafna, S. Space Syntax: A Brief Introduction to Its Logic and Analytical Techniques. Environ. Behav. 2003, 35, 17-29. [CrossRef]

38. Hillier, B. Hanson, J. The Social Logic of Space; Cambridge University Press: Cambridge, UK, 1984; pp. 1-25.

39. Rashid, M.; Kampschroer, K.; Wineman, J.; Zimring, C. Spatial Layout and Face-to-Face Interaction in Offices-A Study of the Mechanisms of Spatial Effects on Face-to-Face Interaction. Environ. Plan. B Plan. Des. 2006, 33, 825-844. [CrossRef]

40. Kweon, Y. A Comparative Study on Centrality in Museum Layouts-In the Case of the Royal Museum of Scotland and Burrell Gallery. J. Asian Arch. Build. Eng. 2002, 1, 205-212. [CrossRef]

41. Haq, S. Investigating the syntax line: Configurational properties and cognitive correlates. Environ. Plan. B Plan. Des. 2003, 30, 841-863. [CrossRef]

42. De Jong, M. Spatial structure and use of school buildings. In Evolving Environmental Ideals_Changing Way of Life, Values and Design Practices: IAPS 14 Conference Proceeding; Royal Institute of Technology: Stockholm, Sweden, 1996; pp. 129-140. 
43. Nayeem, M.N.; Nayeem, H. Thinking accessibility towards excellence in school buildings in relation to the existing and proposed spatial organization using space syntax. Int. J. Sci. Environ. Technol. 2017, 6, 1367-1378.

44. Taguchi, M.; Kishimoto, T. A study on space configuration of elementary schools and children activity in free time. In Proceedings of the 8th International Space Syntax Symposium, Santiago, Chile, 3-6 January 2012.

45. Kishimoto, T.; Taguchi, M. Spatial Configuration of Japanese Elementary Schools: Analyses by the Space Syntax and Evaluation by School Teachers. J. Asian Archit. Build. Eng. 2014, 13, 373-380. [CrossRef]

46. Pasalar, C. The Effects of Spatial Layouts on Students' Interactions in Middle Schools: Multiple Case Analysis. Ph.D. Thesis, North Carolina State University, Raleigh, NC, USA, 2004.

47. Pasalar, C. Spaces for Learning through Better Social Interaction. In School Building Design and Learning Performance: With a Focus on Schools in Developing Countries; Comportements: Lausanne, Switzerland, 2007; pp. 51-60.

48. Mustafa, F.; Rafeeq, D. Assessment of elementary school buildings in Erbil city using space syntax analysis and school teachers' feedback. Alex. Eng. J. 2019, 58, 1039-1052. [CrossRef]

49. Dettlaff, W. Space Syntax Analysis: Methodology of Understanding the Space. PhD Interdiscip. J. 2014, 1, $283-291$.

50. Hillier, B. Space is the Machine: A Configurational Theory of Architecture; Cambridge University Press: Cambridge, UK, 2007.

51. Dursun, P. Space Syntax in Architectural Design. In Proceedings of the 6th International Space Syntax Symposium, Istanbul, Turkey, 12-15 June 2007.

52. Zolfagharkhani, M.; Ostwald, M.J. The Spatial Structure of Yazd Courtyard Houses: A Space Syntax Analysis of the Topological Characteristics of the Courtyard. Buildings 2021, 11, 262. [CrossRef]

53. Jiang, B.; Claramunt, C.; Klarqvist, B. An Integration of Space Syntax into GIS for Modelling Urban Spaces. Int. J. Appl. Earth Obs. Geoinf. 2013, 2, 161-171. [CrossRef]

54. Turner, A. Depthmap 4: A Researcher's Handbook. 2004. Available online: http://www.vr.ucl.ac.uk/depthmap/handbook/ depthmap4.pdf (accessed on 12 October 2020).

55. Klarqvist, B. A space syntax glossary. Nordisk Arkit. Forsk. 1993, 2, 11-12.

56. Vaughan, L. The spatial syntax of urban segregation. Prog. Plan. 2007, 67, 199-294. [CrossRef]

57. Hillier, B.; Vaughan, L. The city as one thing. Prog. Plan. 2007, 67, 205-230.

58. Arslan, H.; Çakmak, B. Syntactic analysis and evaluation on different primary school buildings in Turkey. In Proceedings of the International Conference on Advances in Civil, Structural and Construction Engineering-CSCE, Rome, Italy, 10-11 December 2014.

59. Köken, B.; Arslan, H.D.; Çakmak, B.Y. Comparative Spatial Analysis of a Re-arranged Hospital Building. Int. J. Archit. Environ. Eng. 2015, 9, 1102-1108.

60. Zarnegar, A.; Abediyan, J. Religious schools in Yazd at the age of the Zand and Qajar. Sci. J. Hist. Res. 2014, 9, 35.

61. Babaei, S.; Khakzand, M. Contextualism in the Works of Non-Iranian Architects during the Pahlavi I EraCase Study: Alborz and Iranshahr Schools. J. Iran. Archit. Stud. 2019, 7, 171-189.

62. Mostafazade, M.; Pourman, H. Iranshahr High School, Yazd, 1935-1937: Investigation of a new architectural language for a modern educational institution. In Proceedings of the National Conference on One Hundred Years of Contemporary Iranian Architecture and Urban Planning, Karaj, Iran; 2011.

63. Iravani, S. An Introduction to Explain the Nature of Iran Educational System from Its Modernization time till now. Found. Educ. 2014, 4,83

64. Hayati, H.; RahmatNia, A.; Kavarizadeh, H. Typology of Traditional School Architecture with an Emphasis on the Effect of Educational Policies. Mon. Sci. J. Bagh-E Nazar 2020, 16, 63-84.

65. Mahdavinejad, M.; Qasempour Abadi, M.H.; Mohammadloy Shabestari, A. Typology of mosques in Qajar schools. Iran. Islamic Urban Stud. Q. 2013, 3, 5-15.

66. Gholami, F.; Hayaty, H. Concept of education and its effects on architecture of mosque-schools in qajars era. J. Technol. Educ. 2019, 13, 743-761.

67. Hamzavi, R. A Study of the Social Schools Function with Emphasis on the Ideas of Social Sustainability. Q. Rep. Fars Prov. Build. Eng. Syst. Organ. 2010, 66, 94-99.

68. Gharavi, M. Neighborhood School: Cultural-Social Center for Organizing the Neighborhood. Fine Arts Q. 2005, $21,67-76$.

69. Vasiq, B.; Ghadrdan Gharamaleki, R. The Concept of Education and its impact on the Architecture of Islamic Schools-(A comparative comparison between Seljuk and Safavid Schools). J. Res. Islamic Archit. 2016, 4, 40-57.

70. Ahangari, M.; Motadayen, H. Rethinking in the connection between school and city according to school sociability analysis in Timurid era till early fourteenth century in Iran-Fine Arts: Architecture and Urbanization. In WIT Transactions on the Built Environment; WIT Press: Ashurst, UK, 2017; Volume 8, pp. 75-86.

71. Soltanzadeh, H. History of Iranian Schools from the Time of Antiquity to the Establishment of the Dar-al-fonon School; Agah Publishing Institute: Tehran, Iran, 1985.

72. Schein, E.H.; Bennis, W.G. Personal and Organizational Change through Group Methods: The Laboratory Approach; Wiley: New York, NY, USA, 1965. 